\title{
Valuation of Unlisted Direct Investment Equity
}

\author{
Emmanuel Kumah, Jannick Damgaard, \\ and Thomas Elkjaer
}


IMF Working Paper

Statistics Department

Valuation of Unlisted Direct Investment Equity

Prepared by Emmanuel Kumah, Jannick Damgaard, and Thomas Elkjaer

Authorized by Ralph Kozlow

November 2009

\begin{abstract}

\section{This Working Paper should not be reported as representing the views of the IMF.} The views expressed in this Working Paper are those of the author(s) and do not necessarily represent those of the IMF or IMF policy. Working Papers describe research in progress by the author(s) and are published to elicit comments and to further debate.

This paper analyzes the seven valuation methods for unlisted direct investment equity included in the recently adopted IMF Balance of Payments and International Investment Position Manual, Sixth Edition (BPM6). Based on publicly available Danish data, we test the three methods that are generally applicable and find that the choice of valuation method and estimation technique can have a highly significant impact on the international investment position, pointing to the need for further harmonization. The results show that the price-tobook value method generates more robust market value estimates than the price-to-earnings method. This finding suggests that the valuation basis for the forthcoming Coordinated Direct Investment Survey - own funds at book value - will provide useful information for compiling the international investment position.
\end{abstract}

JEL Classification Numbers: C82, E01, F21, G12

Keywords: Valuation methods, FDI, international investment position, macroeconomic statistical methodology, estimation techniques

Authors’ E-Mail Addresses: ekumah@imf.org; jda@nationalbanken.dk, thoelk@um.dk

\footnotetext{
* Emmanuel Kumah is Chief of the Resource Management Division at the IMF's Statistics Department; Jannick Damgaard is an economist in the External Statistics Division of Danmarks Nationalbank's Statistics Department; Thomas Elkjaer is a counsellor (finance) at the Embassy of Denmark in Beijing on behalf of Danmarks Nationalbank and is currently on leave from the IMF. The main part of this study was carried out in 2007-2008 when Thomas Elkjaer was working in the Balance of Payments Division at the IMF's Statistics Department, and Jannick Damgaard was visiting the division. The authors are truly grateful to Ralph Kozlow (Chief of the Balance of Payments Division at the IMF's Statistics Department) for guidance and useful comments provided during the project.
} 


\section{Table of Contents}

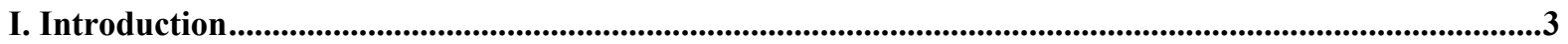

II. Valuation of Equity .................................................................................................................................

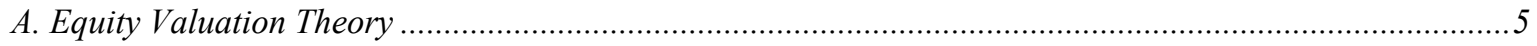

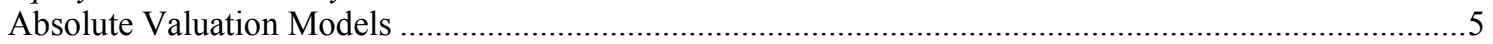

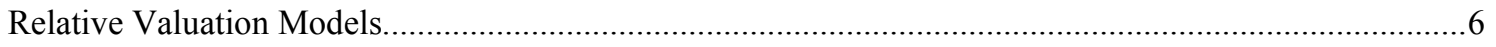

B. Valuation in International Macroeconomic Statistical Manuals ........................................................... 10

C. Issues Related Particularly to Valuation of Unlisted Equity ............................................................... 13

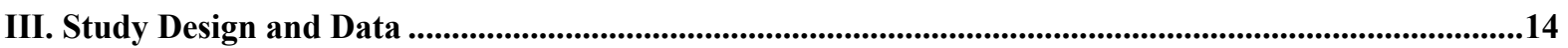

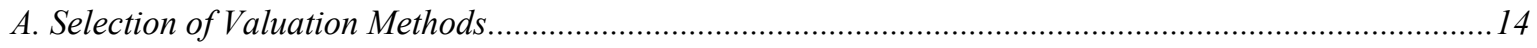

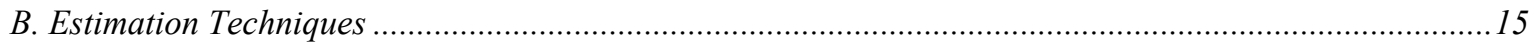

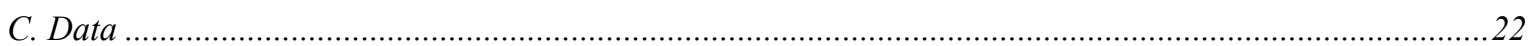

IV. Empirical Modeling of Market Value Estimates................................................................................................27

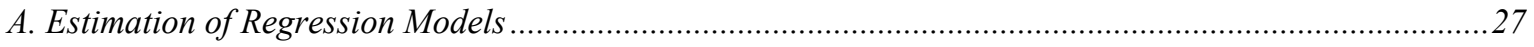

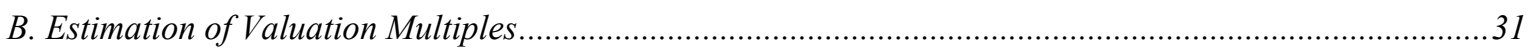

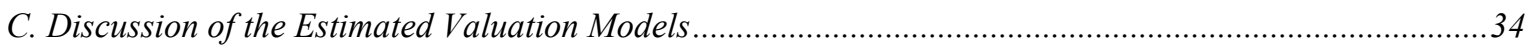

V. Application of Models to the Danish International Investment Position ........................................................36

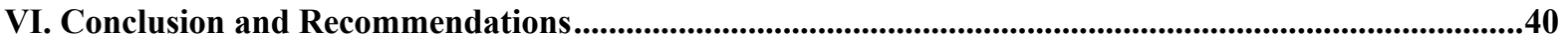

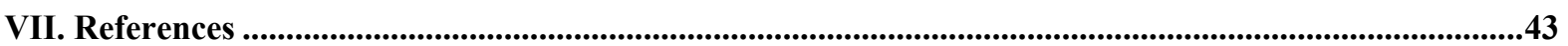

Annex 1: BPM6-Recommended Valuation Methods...............................................................................................45

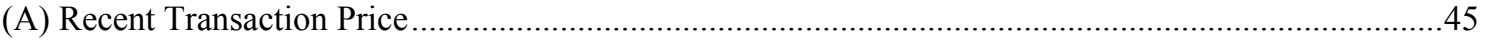

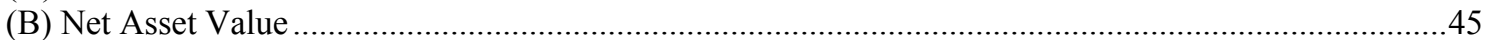

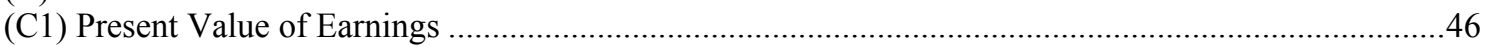

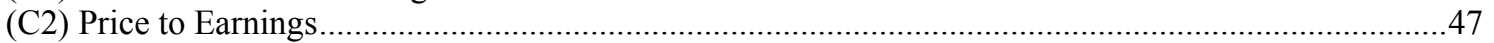

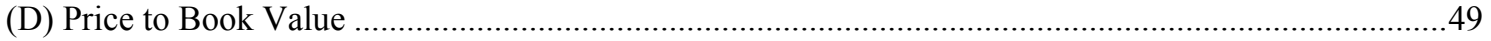

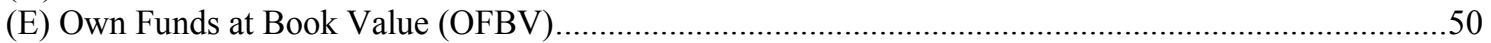

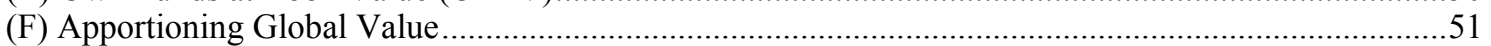

Annex 2: Issues Related Particularly to Valuation of Unlisted Equity ..............................................................52

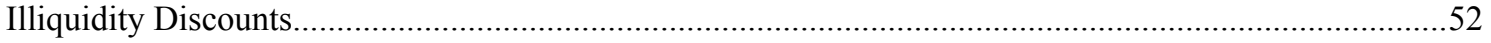

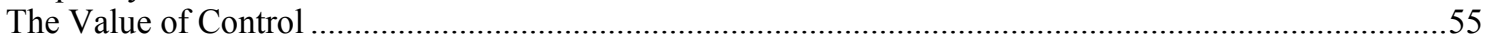

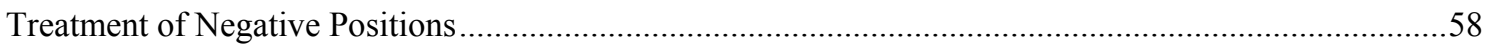

Annex 3: Model Assumptions ..............................................................................................................................60

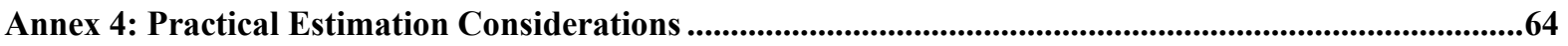

Annex 5: Descriptive Statistics for Unlisted Direct Investment Enterprises...................................................71

Annex 6: Practical Advice for Compilers........................................................................................................ 


\section{INTRODUCTION}

The compilers' choice of valuation method and estimation technique can have a substantial effect on official foreign direct investment (FDI) figures, which for many countries make up a significant part of their international investment position (IIP). In some cases, the choice of method and technique can fundamentally change a country's IIP. In international macroeconomic statistical manuals, market prices are the preferred principle for valuation of financial instruments. While this is straightforward for financial instruments that are traded regularly in the markets, valuation is much more complicated for unlisted equity because market prices cannot be directly observed and therefore have to be estimated. ${ }^{1}$

Differences in country practices for valuing unlisted equity make it difficult to achieve the important statistical objective of international comparability, including bilateral symmetry. For instance, Kozlow (2002) shows that applying different valuation methods can significantly change the IIP of the US. This illustrates the risk that statistical data could be misleading and lead to erroneous analysis or policy recommendations. For example, if the inward FDI position is used as an indicator for the attractiveness of investing in a country, the outcome of such analysis could largely depend on the choice of valuation method unless there are specific guidelines in place to ensure reliable and robust market value estimates.

To address the valuation issue, the IMF's Balance of Payments and International Investment Position Manual, Sixth Edition (BPM6) contains a shortlist of recommended methods to estimate market value equivalents for unlisted direct investment equity. This shortlist also provides guidance to compilers on the methods and their suitability depending on a country's specific circumstances.

The purpose of this paper is to investigate to what extent the shortlisted methods reduce the valuation issues. The methods should produce both reliable market value equivalents and robust results. If a method generates similar estimates for market values when different estimation techniques are applied, that method is considered robust. The discrepancy between the highest and lowest estimate, when applying different valuation

\footnotetext{
${ }^{1}$ Since most unlisted equity in the IIP is in direct investment rather than portfolio investment, this valuation problem primarily affects direct investment equity.
} 
methods and estimation techniques, can be interpreted as the range for possible bilateral asymmetries within the BPM6-recommendations. ${ }^{2}$

In this paper, the practical effects of applying different valuation methods and estimation techniques are illustrated on the Danish IIP. ${ }^{3}$ The effects can be very significant, for instance, just applying different estimation techniques to one of the BPM6-recommended valuation methods, the commonly used price-to-earnings method, generates a difference corresponding to $63 \%$ of the total liabilities in the official Danish IIP. Even if these empirical findings are not generally applicable, the large differences clearly point to the need to pay close attention to the practical considerations in estimating FDI positions.

The empirical test in this study will be limited in two ways. First, only a subset of the recommended methods will be tested. This is due to data availability and the limited general applicability of some of the methods. Second, the test is limited to only one dataset, i.e. a detailed dataset for Nordic companies, in order to eliminate valuation issues arising from the use of varying datasets. In practice, compilers could use all the recommended methods and several different datasets, and, hence, the potential bilateral asymmetries within the BPM6recommendations may be even higher than suggested in this study. Therefore, steps should clearly be taken to create increased cross-country harmonization in valuation principles for unlisted direct investment equity in the future. ${ }^{4}$

The remainder of the paper is organized as follows. Section 2 describes the general theories of equity valuation and links these to the valuation methods recommended in the BPM6. In Section 3, the study design and data are presented while Section 4 estimates, compares and discusses the empirical models. The results are applied to the Danish IIP in

\footnotetext{
${ }^{2}$ Data quality issues, like lack of coverage or difficulties with geographical allocation, are also typical sources for bilateral asymmetries, but these issues are naturally not within the scope of the recommended valuation methods in the BPM6.

${ }^{3}$ Like many other countries, Denmark is currently using own funds at book value for the valuation of unlisted equity, but is considering the implementation of another method to estimate market values. Denmark has been chosen as the case study for this paper due to Danmarks Nationalbank's interest in testing new market valuation methods. Danmarks Nationalbank is the official Danish IIP compiler and has kindly provided access to Danish company specific data for the purpose of this exercise.

${ }^{4}$ The Statistics Department of the IMF is currently implementing the Coordinated Direct Investment Survey (CDIS) with the purpose of obtaining detailed position data on direct investment. In order to promote data consistency across countries, the IMF recommends a symmetric valuation principle for this exercise.
} 
Section 5. Section 6 presents the conclusions and offers suggestions for improving market value approximations and reducing bilateral asymmetries.

\section{VALUATION OF EQUiTy}

\section{A. Equity Valuation Theory}

The numerous theoretical models for equity valuation can be split into two groups; absolute and relative valuation models. ${ }^{5}$ In absolute valuation models, the value of equity is determined by the specific characteristics of the particular company. This value may or may not be equal to the market price, depending on the assessment of future earnings and risks compared to market expectations. Most absolute valuation models are based on a discounted cash flow (DCF) approach. In the relative valuation models, a company is valued at the same price as companies with identical or similar characteristics since, for arbitrage reasons, similar assets must trade at similar prices. One of the most used relative valuation models is price to earnings $(\mathrm{P} / \mathrm{E})$.

\section{Absolute Valuation Models}

The underlying idea of most absolute valuation models is that the fundamental value of an asset equals future cash flows discounted with the investors' required risk adjusted rate of return. The most simple absolute valuation model is the Gordon Growth Model (GGM):

$$
V_{0}=\frac{D_{0}(1+g)}{r-g} \text { for } r>g
$$

where $V_{0}$ is the equity value at time $0, D_{0}$ is the dividend in period $0, g$ is the expected dividend growth rate, and $r$ is the required rate of return. The required rate of return is the sum of the risk-free interest rate and a risk premium.

\footnotetext{
${ }^{5}$ The valuation theory applies to both listed and unlisted equity; issues specific for unlisted equity are discussed in Section 2C.
} 
Higher dividend growth rate will increase the value of the equity. Similarly, lower risk-free interest rate and/or risk premium will increase the equity value. It is intuitive that higher earnings, lower risk, and lower returns on alternative investments have positive effects on the value of the asset. The value is particularly sensitive to changes in the expected dividend growth since it affects both the numerator and the denominator.

The GGM rests on a number of assumptions. It assumes that there is an even relationship between dividends and earnings, and constant dividend growth. Moreover, it requires that the risk premium is constant and can be estimated. In practice, relative valuation models like the capital asset pricing model (CAPM) and arbitrage pricing theory model (APT) are often used to estimate the risk premium (Damodaran, 2002).

There are several varieties of the DCF models that allow for growth to change over time and cash flows to be defined differently. Dividends are often distributed on an irregular basis, especially for unlisted equity. Consequently, dividends are typically replaced by earnings when the model is used in practice. Even though DCF is theoretically the best way to value equity, absolute valuation models are not widely used in practice. The main reasons are the uncertainties related to risk premium and expected future earnings estimates combined with the large sensitivity in the equity value to small changes in these estimates (Stowe, Robinson, Pinto, and McLeavey, 2002).

\section{Relative Valuation Models}

The relative valuation models rest on the law of one price (LOOP), which states that similar assets must trade at similar prices for arbitrage reasons. If not, a risk-free premium could be earned by buying the underpriced asset and short-selling the overpriced asset. Therefore, the idea is not to find the fundamental value and then determine whether a company is undervalued, fairly valued, or overvalued as in the absolute valuation models. Instead, the price of a company is compared to the prices of similar equities to determine whether it is relatively undervalued, fairly valued, or overvalued.

In the relative valuation models, just as in the absolute valuation models, the value of equity depends on future expected cash flows and risk premiums. However, rather than directly estimating the company's cash flows and risks, a different company that is believed to have the same cash flows and risk profile is found. In its simplest form, the relative 
valuation model states that two assets with identical characteristics with respect to earnings and risks are valued at the same price. Using the same assumptions and notation as in the GGM, the relative valuation model in its simplest form is given by:

$$
\begin{gathered}
V_{i t}=V_{j t} \\
\text { if } D_{i 0}=D_{j 0}, r_{i}=r_{j} \text {, and } g_{i}=g_{j},
\end{gathered}
$$

where subscript $i$ denotes the company that is being valued, $j$ denotes the comparable company, and $t$ indicates time. The key is to find companies with the exact same characteristics as the one that is being priced, for instance companies that are traded on more than one stock exchange. Levy Yeyati, Schmuckler, and Van Horen (2006) find that the LOOP holds well for such companies, especially in liquid markets with limited capital controls.

Naturally, for most equity, it is not possible to find companies that are sufficiently close substitutes, and a synthetic arbitrage relation is constructed instead. This means that comparable companies are allowed to differ on one factor, for instance dividends (earnings), thus making it easier to find comparables. This can be incorporated into Equation 2.2, and the value of company $i$ at time $t$ is:

$$
V_{i t}=V_{j t}\left(F_{i \tau}\left(F_{j \tau}\right)^{-1}\right)
$$

where $F$ is the factor that is allowed to vary between companies proportionally to market value of the equity, and $\tau$ denotes the time at which the factors are measured. It is preferred that $\tau$ and $t$ be identical, but often this is not possible due to lack of data, and rather it is assumed that the relationship between factors at time $t$ is the same as it was at time $\tau$.

Common examples of factors are earnings, sales, and cash flows. The single-factor model is often rearranged to be expressed as a valuation multiple (a ratio); for instance, the price-to-earnings $(\mathrm{P} / \mathrm{E})$ ratio. ${ }^{6}$ Valuation multiples are used to compare what investors are

\footnotetext{
${ }^{6}$ Valuation multiples are typically calculated as price per share divided by factor units per share. The focus of this study is to estimate the value of the whole company, so it is not necessary to divide by number of shares, cf.
}

(continued...) 
paying for one unit of the factor included in the model. If the $\mathrm{P} / \mathrm{E}$ ratio for a company is lower than for its peers, it indicates that the company is relatively undervalued. Sometimes, price-to-book value $(\mathrm{P} / \mathrm{B})$ ratios are used even though book value is a stock variable, which does not necessarily approximate future cash flows. On the other hand, book value is normally less volatile than flow variables such as earnings and does often result in more stable ratios for this reason. Furthermore, book value normally reflects past earnings to some extent. In that sense, the $\mathrm{P} / \mathrm{B}$ ratio does indirectly take earnings into account as suggested in the theory of equity valuation, but in a less explicit manner than in the theoretical framework

In practice, the multiple of a company is compared to multiples for a peer group of companies rather than just one. The peer group typically consists of companies in the same industry group and of similar size, based on the assumption that future earnings and risk premiums are identical or similar for such companies.

If debt financing ratios vary across the peer group, multiples on enterprise value (EV) are often used instead of equity value. EV is defined as the sum of market value of debt, common equity, and preferred equity minus the value of cash and investments. The idea is that EV measures are less sensitive to differences in financial leverage since they take into account the entire value of the company and not just the equity (Koller, Goedhart, and Wessels, 2005). For EV ratios, earnings before interest and taxes (EBIT) are normally used as the earnings measure because EBIT as a pre-interest figure can be regarded as a flow to all providers of capital whereas net income only accumulates to the shareholders. For the same reason, it is not advised to use price-to-sales $(\mathrm{P} / \mathrm{S})$ ratios for companies with differences in financial leverage since the proceeds from sales flow to all providers of capital and not just shareholders. Hence, EV/S ratios make more sense from a theoretical point of view.

In the single-factor model, peer companies share exactly the same characteristics except for the factor used in the model. In practice, it may not be possible to find such companies, and multi-factor models, where several factors vary across the companies in the peer group, are used. This makes it possible to compare synthetically identical assets. Building on the framework of Equation 2.3, the value of company $i$ at time $t$ is given by:

Equation 2.3. However, we still use the common notation for multiples with price per share $(P)$ in the numerator instead of market value of the company $(V)$ since price-per-share multiples are well-known. This has no practical implications since the number of shares is excluded from both the numerator and the denominator. 


$$
V_{i t}=V_{j t} \sum_{n=1}^{x}\left(a_{n t}\left(F_{i n \tau}\left(F_{j n \tau}\right)^{-1}\right)\right),
$$

where $n$ denotes the different factors, $x$ is the total number of factors, and $a_{n t}$ represents the weighting of factor $n$ at time $t$. Naturally, $\sum_{n=1}^{x} a_{n t}=1$, for all t. In practice, multi-factor models are often estimated by regression analysis due to the difficulties connected with the determination of weights (Meitner, 2006). The regression models will include market value of equity or $\mathrm{EV}$ as the dependent variable and the factors as independent variables.

A general weakness of the relative valuation models is that the estimates are often based on accounting data. Despite attempts to harmonize accounting regulations through the International Financial Reporting Standards (IFRS) ${ }^{7}$ or local Generally Accepted Accounting Principles $(\mathrm{GAAP})^{8}$, there is still considerable room left for different interpretations. Therefore, even if indicators such as past earnings and sales can be seen as perfect proxies for future earnings ${ }^{9}$ and all companies in a peer group are in fact exposed to the same risks, there could still be differences in valuation multiples that were simply caused by accounting differences rather than real economic differences.

Nevertheless, the relative valuation models based on accounting data are widely used for equity valuation in practice (Hitchner, 2006). Their main advantages are simplicity, data availability and the use of reference companies, which makes the assessment process less demanding in terms of data needs and assumptions about future earnings. Typically, a

\footnotetext{
${ }^{7}$ The terms International Accounting Standards (IAS) and IFRS are often used interchangeably. IAS refer to the standards introduced by the International Accounting Standard Committee (IASC) in the period 1973-2001 while IFRS refer to standards issued by the successor for the IASC, namely the International Accounting Standard Board (IASB), since 2001. For simplicity, this study uses the term IFRS for both sets of international accounting standards.

${ }^{8}$ GAAP is often used as an acronym for US Generally Accepted Accounting Principles, but the term local GAAP does not refer to the accounting principles in a specific country in this study.

${ }^{9}$ The relative models are often criticized for being based on historical data or data at a given point in time. However, the models can easily be adjusted to including estimates for future earnings (cf. Box 1), as is the theoretical foundation for equity valuation.
} 
number of different multiples will be calculated, and information from an absolute valuation model may be included when buy-sell recommendations are made in practice.

\section{BOX 1: INCLUDING FUTURE EARNINGS IN RELATIVE VALUATION MODELS}

A main weakness of most relative valuation models is that they are based on historical data and therefore do not take future earnings into account, which is what is relevant. If companies in a peer group only share the same risks, but not the same expected future earnings, it will be misleading to compare $\mathrm{P} / \mathrm{E}$ ratios since growth in earnings will differ. The concept of price-earnings-to-growth (PEG) ratios has been developed to address this problem. It is a special case of the multi-factor model where $\mathrm{P} / \mathrm{E}$ ratios are divided by the expected earnings growth rate in order to take future differentials into account. Adjusting Equation 2.4, the value of company $i$ at time $t$ is given by:

$$
V_{i t}=V_{j t} E_{i \tau}\left(E_{j \tau}\right)^{-1} g_{j}\left(g_{i}\right)^{-1}
$$

where $E$ represents earnings, and $g$ denotes the earnings growth rate. A high $\mathrm{P} / \mathrm{E}$ ratio is justified if earnings growth is expected to be high. Despite taking growth differentials into account, the PEG method is not a panacea since forecasts of earnings growth are fundamentally associated with a high degree of uncertainty, as is also the case for the absolute valuation models.

\section{B. Valuation in International Macroeconomic Statistical Manuals}

Market value is the general valuation principle in the BPM6 and other international macroeconomic statistical manuals. ${ }^{10}$ For position data, the term market value is defined as the value of assets or liabilities using the closing market prices on the balance sheet reporting date. If financial instruments are not traded in a market or only traded infrequently, a market equivalent value should be estimated instead. This value is also referred to as fair value and is defined as "the amount for which an asset could be exchanged, or a liability settled, between knowledgeable, willing parties in an arm's-length transaction" (BPM6, paragraph $3.88)$.

\footnotetext{
${ }^{10}$ The exceptions include positions in loans, deposits, and accounts receivable/payable, which are recorded at nominal value. According to the BPM6 (paragraph 3.86), this can partly be explained by pragmatic concerns such as data availability and symmetric cross-country recording, but also by the fact that nominal value constitutes the legal value in case of bankruptcy.
} 
As a new feature, the BPM6 (paragraph 7.16) includes a list of seven ${ }^{11}$ methods recommended for estimating market values of shareholder equity in unlisted direct investment enterprises. The list includes absolute as well as relative valuation methods. ${ }^{12}$ All methods have their individual strengths and weaknesses, and different methods are preferable in different circumstances, particularly depending on data availability, which is often the main constraint that compilers have.

Table 1 provides an overview of the recommended methods and their pros and cons. ${ }^{13}$

\footnotetext{
${ }^{11}$ In principle, the BPM6 (paragraph 7.16) includes a list of only six methods, but the method presented in paragraph 7.16(c) can been seen as a combination of two methods, and these will be treated separately in this study.

12 The absolute valuation methods are in this context defined as methods, which value companies without a reference to other companies with similar characteristics. In valuation theory, the absolute valuation models usually apply an income approach and discount future cash flows. However, other types of information used to value a specific company directly may also be regarded as absolute valuation. For instance, if valuation is based on accounting data, and no reference is made to other companies, this will be regarded as an absolute valuation method.

${ }^{13}$ In Annex 1, each method is described in detail, including advantages and disadvantages in relation to equity valuation theory and practical considerations.
} 
Table 1: Overview of BPM6-recommended valuation methods and their advantages and disadvantages

\begin{tabular}{|c|c|c|c|c|}
\hline Method & Name & Description & Advantages & Disadvantages \\
\hline A & $\begin{array}{l}\text { Recent transaction price } \\
\text { (absolute method) }\end{array}$ & $\begin{array}{l}\text { Use recent transaction price as } \\
\text { market price }\end{array}$ & $\begin{array}{l}\text { - Easy to implement for traded equity } \\
\text { - Equals market price at time of transaction } \\
\text { by definition }\end{array}$ & $\begin{array}{l}\text { - Market prices can change rapidly } \\
\text { - Not a general method because most } \\
\text { unlisted equity is rarely traded }\end{array}$ \\
\hline B & $\begin{array}{l}\text { Net asset value } \\
\text { (absolute method) }\end{array}$ & $\begin{array}{l}\text { Knowledgeable management } \\
\text { or independent auditors' } \\
\text { estimation of total assets } \\
\text { minus liabilities (excluding } \\
\text { equity) at current value }\end{array}$ & $\begin{array}{l}\text { - Utilizes first-hand information about the } \\
\text { company's value } \\
\text { - Possible to take company-specific } \\
\text { characteristics into account }\end{array}$ & $\begin{array}{l}\text { - Uncertain that respondents use uniform } \\
\text { principles } \\
\text { - Companies may have an incentive to give } \\
\text { incorrect estimates }\end{array}$ \\
\hline $\mathrm{C} 1$ & $\begin{array}{l}\text { Present value of } \\
\text { earnings } \\
\text { (absolute method) }\end{array}$ & $\begin{array}{l}\text { Discount expected future } \\
\text { earnings }\end{array}$ & $\begin{array}{l}\text { - The theoretically best way to value equity } \\
\text { - Possible to capture expectations to future } \\
\text { earnings at company level }\end{array}$ & $\begin{array}{l}\text { - Very time-consuming if done properly } \\
\text { - Based on subjective estimates } \\
\text { - Approximates fundamental value rather } \\
\text { than market value } \\
\text { - Assumes that future earnings are known }\end{array}$ \\
\hline $\mathrm{C} 2$ & $\begin{array}{l}\text { Price to earnings } \\
\text { (relative method) }\end{array}$ & $\begin{array}{l}\text { Apply } \mathrm{P} / \mathrm{E} \text { ratios from listed } \\
\text { equity to unlisted equity }\end{array}$ & $\begin{array}{l}\text { - Easy to implement } \\
\text { - Based on actual market values }\end{array}$ & $\begin{array}{l}\text { - Does not take company-specific } \\
\text { characteristics into account. } \\
\text { - Assumes that a model based on listed } \\
\text { equity can be transferred to unlisted } \\
\text { equity }\end{array}$ \\
\hline $\mathrm{D}$ & $\begin{array}{l}\text { Price to book value } \\
\text { (relative method) }\end{array}$ & $\begin{array}{l}\text { Apply } \mathrm{P} / \mathrm{B} \text { ratios from listed } \\
\text { equity to unlisted equity }\end{array}$ & $\begin{array}{l}\text { - Easy to implement } \\
\text { - Based on actual market values }\end{array}$ & $\begin{array}{l}\text { - Does not take company-specific } \\
\text { characteristics into account } \\
\text { - Assumes that a model based on listed } \\
\text { equity can be transferred to unlisted } \\
\text { equity }\end{array}$ \\
\hline $\mathrm{E}$ & $\begin{array}{l}\text { Own funds at book } \\
\text { value } \\
\text { (absolute method) }\end{array}$ & $\begin{array}{l}\text { The sum of paid-up capital, } \\
\text { reserves, cumulated } \\
\text { undistributed net profits, and } \\
\text { holdings gains and losses } \\
\text { included in own funds }\end{array}$ & $\begin{array}{l}\text { - Easy to implement } \\
\text { - Promotes symmetric recording if used by all } \\
\text { countries }\end{array}$ & $\begin{array}{l}\text { - Book values do not necessarily reflect } \\
\text { market values } \\
\text { - Accounting principles differ across } \\
\text { countries }\end{array}$ \\
\hline $\mathrm{F}$ & $\begin{array}{l}\text { Apportioning global } \\
\text { value } \\
\text { (absolute method) }\end{array}$ & $\begin{array}{l}\text { Prorate overall market value } \\
\text { of listed group to individual } \\
\text { entities }\end{array}$ & $\begin{array}{l}\text { - Based on the actual market value of the } \\
\text { specific group } \\
\text { - Straightforward to make the estimations }\end{array}$ & $\begin{array}{l}\text { - Difficult to find the best apportioning } \\
\text { indicator } \\
\text { - Not a general method because many } \\
\text { unlisted direct investment enterprises are } \\
\text { not a part of a listed group }\end{array}$ \\
\hline
\end{tabular}




\section{Issues Related Particularly to Valuation of Unlisted Equity}

In addition to the difficulties already described with regard to valuation of equity, there are other issues that further complicate the valuation of unlisted equity and set it apart from the valuation of listed equity. The three main issues are (i) liquidity, (ii) the value of control, and (iii) negative equity values. ${ }^{14,15}$ These complications apply to both absolute and relative valuation methods and are only briefly or indirectly discussed in international macroeconomic statistical manuals even though they can have significant impact on valuation of equity and are discussed extensively in equity valuation theory. First, unlisted equity is most often characterized by lower degree of liquidity than listed equity. A lower degree of liquidity tends to have a negative effect on prices, and if significant, it should be taken into account in the valuation.

Second, unlisted companies usually have very few owners, often even just a single investor. A control premium is frequently included when investors obtain a controlling stake in a company because investors believe that they can increase the value of the company through efficiency gains. However, it can be argued that this control premium will be offered to all shareholders. Thus, all shares in a given company should be valued at a uniform price. ${ }^{16}$

Third, valuation methods do in a number of cases generate negative equity positions. It may be argued that such negative equity positions in direct investment enterprises should not be recorded in the IIP as direct investors would not be liable for any losses exceeding the capital invested in the enterprises. On the other hand, many direct investment enterprises are

\footnotetext{
${ }^{14}$ This paper applies the asset/liability principle as presented in the BPM6 standard components rather than the directional principle, which is described in the BPM6 (paragraphs 6.42-6.43). Under the directional principle, a negative position could be recorded if, for example, a large reverse equity position existed between the direct investment enterprise and its direct investor, or if cumulative retained earnings were negative. Also, a negative equity position would be recorded in the case where a seller of a direct investment enterprise is willing to pay a potential buyer of that enterprise to take over ownership; such a situation may occur in the case where a government has assumed control over an insolvent financial institution.

${ }^{15}$ The empirical results presented in Sections 4 and 5 quantify the effects of including a liquidity variable in the valuation models as well as the potential impact of negative values. In order to give a deeper understanding of the three issues and their importance for valuation of unlisted direct investment equity, they are discussed in detail in Annex 2.

${ }^{16}$ This would not necessarily be the case in countries with low protection of minority shareholders as controlling investors would be able to reap private benefits (cf. Annex 2).
} 
quasicorporations such as branches and notional units created for statistical purposes, and the direct investor would be liable for the debts of these units. Moreover, direct investment enterprises are often owned by a single direct investor who may recapitalize the direct investment enterprise in times of financial distress. Also, sometimes direct investors are held liable for the losses of their direct investment enterprises (such as where they have provided an explicit guarantee, or where the direct investment enterprise has caused damage or public harm). BPM6 allows the inclusion of negative direct investment equity positions in the IIP, but some individual country practices differ. It may thus be preferable to use a valuation method that is based on a valuation indicator that rarely takes on negative values and in such cases only small values.

\section{Study Design ANd DATA}

\section{A. Selection of Valuation Methods}

The purpose of this empirical study is to test the reliability and robustness of the BPM6recommended valuation methods. While each method has different strengths and weaknesses, the empirical study in this paper will be limited to three of the seven methods. Two methods based on the relative valuation models; price to earnings (Method C2) and price to book value (Method D), and one method based on the absolute valuation model; own funds at book value (Method E).

There are a number of considerations for limiting the study to these three methods. First, we have chosen methods that can be based on publicly available information rather than methods where the compiler has to make subjective assumptions about a company because, while the individual country compiler might be able to do this in a somewhat uniform way, it is much less likely to be the case for compilers across countries, potentially leading to bilateral asymmetries. This eliminates present value of earnings (Method $\mathrm{C} 1$ ), which requires assumptions to be made about future earnings. It also eliminates net asset value (Method B) as it requires inside or first-hand information about a company, which compilers rarely have. Second, we have chosen methods that are general in the sense that the needed data generally are available for all or most companies, thus eliminating recent transaction price (Method A). The reason is that while this method is easy to implement and 
robust, it requires that a recent transaction price exists, which is typically not the case for unlisted equity. This consideration also eliminates apportioning global value (Method F) because many unlisted direct investment enterprises are not a part of a listed group.

This leaves three methods that are based on common publicly available data, namely price, earnings, and book values. ${ }^{17}$ It is important to point out that limiting the empirical study to three methods is not an indication that the excluded methods are inferior; for instance, the recent transaction price method will often give the best market value equivalents for direct investment enterprises that have been traded recently.

\section{B. Estimation Techniques}

This section presents the standard estimation techniques applied for the practical estimation of valuation models. The BPM6 provides open definitions of the relative valuation methods in the sense that it does not give specific recommendations regarding the estimation techniques. Consequently, bilateral asymmetries are possible if the estimation techniques do not produce robust results. Typically, compilers would either estimate market values through a regression approach or calculate central tendency measures for valuation multiples, which would subsequently be applied to the data for unlisted direct investment equity.

\section{Regression Models on Market Value}

The underlying idea of the regression approach is to estimate a simple ordinary least squares (OLS) model, which can be applied to unlisted direct investment equity at the company level. ${ }^{18}$ This approach has two apparent advantages over central tendency measures for valuation multiples such as $\mathrm{P} / \mathrm{B}$ or $\mathrm{P} / \mathrm{E}$ ratios. First, multi-factor regression models do not need weights for the input variables as otherwise needed in Equation 2.4. Second, estimations

\footnotetext{
${ }^{17}$ In addition, we will estimate EV valuation models to test if they perform better than models on market value of equity. As mentioned in Section 2A, EV models are less sensitive to differences in financial leverage, and they also meet the criteria of general applicability and being based on publicly available data.

${ }^{18}$ As mentioned in the BPM6 (paragraphs 4.54-4.56), data may be collected by institutional units or by local enterprise groups. The two collection methods are equally acceptable, and valuation models can thus be applied at either of the two levels.
} 
of regression models on market value are not restricted to positive observations in the independent variables as calculations of valuation multiples are.

When estimating valuation models for specific industry groups, the peer group of similar companies may be so small that the number of parameters is higher than the number of observations, leaving too few degrees of freedom for the regression approach. However, in macroeconomic statistics, where focus is on the accuracy of the aggregates, larger but unsystematic company-specific estimation errors and thus peer groups with a larger degree of heterogeneity are acceptable. The basic framework for the estimations is given by:

$$
\boldsymbol{Y}=\boldsymbol{X} \boldsymbol{\beta}+\varepsilon
$$

where $\boldsymbol{Y}$ is a column vector of market values or EV, depending on the model. The design matrix, $\boldsymbol{X}$, includes a column of ones, i.e. a constant term, and a number of quantitative and qualitative variables related to future earnings and risk. The constant term ensures that the models, unlike valuation multiples, may generate positive market values even if the input variables are negative. Moreover, interaction terms between different independent variables are included in the design matrix. The parameter estimates are represented by the column vector $\boldsymbol{\beta}$ and the error terms by the column vector $\boldsymbol{\varepsilon}$.

The rationale for including interaction terms is that the entire effect of certain variables is not necessarily picked up by a level term. For instance, if a country dummy variable for Denmark was included in a Nordic dataset, and it turned out that Danish companies were ceteris paribus priced higher than companies from other Nordic countries, the difference would be expected to vary across companies due to scale differences. The effect is likely to be higher in absolute terms for large companies than for small companies, and the interaction term will capture this effect.

It can also be seen that time is not taken into account in the model specification. In principle, it is possible to estimate the model at any point in time, and if new input data for the independent variables in the model, for instance new accounting data, have not been made available, the parameter estimates will change when the stock markets and equity 
prices move. ${ }^{19}$ The drivers of financial markets change over time, meaning that not only the parameter estimates will change but also the relevant variables. Theoretically, it will only be correct to estimate market values of equity based on data at the exact time of interest. However, for countries with limited depth in stock markets, IIP compilers can use the pooled OLS method in order to obtain more observations for the estimations. ${ }^{20}$ Also, the pooled OLS approach may be used if compilers, for practical reasons, estimate a model, which will be used for a number of periods. The rationale is that the multi-period model is less likely to reflect unusual events in the stock markets that may be prevailing at a specific point in time.

The main weakness of the regression approach is that the parameter estimates may be affected by scale effects. The phenomenon may occur in cases where accounting data for companies of different sizes are used. Small companies often have small values for most variables while large companies have large values for most variables. Large values will dominate the other values in a regression analysis and can lead to distorted parameter estimates if variables correlated with both the dependent and the independent variables are omitted from the model. This will create a bias in the parameter estimates and an overestimation of the coefficient of determination. ${ }^{21}$

Another drawback is that multicollinearity, i.e. high correlation between the independent variables, may occur due to the scale differences and may also lead to biased results. As a rule of thumb, one has to be careful with the interpretation of parameter estimates when

\footnotetext{
${ }^{19}$ This is the point made in Equation 2.3. The input factors are not necessarily observed at the same time as the values, but the relationship between the factors in the model is assumed to be the same at the time of valuation as at the time of measurement.

${ }^{20}$ The pooled OLS regression models use all observations in a panel dataset, not taking the time dimension into account. It would not make sense to estimate panel data models such as fixed and random effects models for the purpose of this analysis. The reason is that these models include an unobserved company-specific element. Since the model has to be transferred to other companies, all independent variables are needed directly in the model to explain variation in equity value.

${ }^{21}$ Christie (1987) points out that return regressions should be used instead of level-based regressions in order to only catch the experimental period and not initial differences, but this approach is not feasible when level-based estimates are the objective as is the case in this study. Barth and Kallapur (1996) recognize this and recommend deflating all variables by the true scale factor if it is known. Veira (2006) argues that the issue of scale effects is a purely econometric phenomenon that can be solved by using logarithmic transformations of the variables in the models. However, $\log$ transformations can only be made for positive values and would exclude companies with negative earnings and book values in the estimation as well as in the application of the models. As we need models that can be applied to all direct investment enterprises, we estimate regression models on the nontransformed data and monitor signs of scale effects in the results.
} 
correlation between independent variables exceeds 0.7 because the variables to a large extent convey the same information.

Heteroscedasticity, i.e. non-constant variance, may still exist in the error term even if scale effects are prevented by adding scale proxies to the valuation model. This does not result in biased parameter estimates, but leads to an underestimation of standard errors and consequently a risk of including insignificant variables in the model unless a correction is made. To address this issue, the adjustment of standard errors as proposed by White (1980) is made in the level-based regression models.

\section{Central Tendency Measures for Valuation Multiples}

Central tendency measures can be the solution if the parameter estimates in the OLS regression model are affected by scale effects or multicollinearity. For single-factor models based on multiples, like P/E and P/B ratios, a range of central tendency measures can be calculated, cf. Table 2. In principle, valuation multiples are only defined when the denominator is positive. However, companies with non-positive earnings/book values may be included in the calculation of valuation multiples at the industry level as the industry sum of these variables is likely to be positive. Even though the calculation of valuation multiples is restrained to observations with positive denominator values, the multiples may in practice be applied to all companies even if they have negative earnings/book values, thus leading to the estimation of negative positions. This would correspond to applying a single-factor regression model without a constant term. In other words, the method would yield negative market value approximations for equities in companies with negative book values while equities in companies with positive book values would have positive market values according to the method.

Additional factors, such as liquidity, cannot be included directly in valuation multiples, but can be introduced by applying the average illiquidity discount from the liquidity studies presented in Annex 2 to the estimated multiples. One of the main drawbacks

of central tendency measures is that a set of predetermined weights is needed to estimate multi-factor models, including both earnings and book value. On the positive side, the central tendency measures are less likely to be dominated by data of a few large companies than the OLS regression approach. Moreover, the measures are generally more stable than the multi- 
factor regression approach since they only include a single variable, meaning that multicollinearity will not be an issue.

As mentioned, the BPM6 does not specifically suggest which central tendency measure should be used for the estimation of valuation multiples, but Table 2 provides a list of five common measures. In an ideal world, all central tendency measures would be identical within a peer group because the single factor would be able to explain all variation in market value. In practice, however, this is unlikely, and the parameter estimate in the single-factor valuation model will vary with the choice of central tendency measure. There is no general rule to determine the appropriate measure. It depends on the distribution of the multiples, the proportion and size of the negative values, and the expected distribution of multiples for unlisted equity. ${ }^{22}$

If compilers observe robust multiples with low dispersion, they will be in a position to use one of the important attributes of the regression approach, namely the inclusion of several independent variables without constructing weights. The reason is that it is then possible to construct a new variable consisting of company-specific multiples and carry out a multivariate regression analysis with valuation multiples as the dependent variable after the exclusion of the top $5 \%$ and bottom $5 \% .^{23}$ This means that it is not necessary to define the peer group prior to the calculation of multiples, and a liquidity variable can be included directly in the analysis.

\footnotetext{
${ }^{22}$ This is further elaborated in Box 2, which contains guidelines for the evaluation of the validity and reliability of the valuation models.

${ }^{23}$ This corresponds to deflating the left-hand side of Equation 3.1 by the factor in the univariate model and adding the extra factors on the right-hand side. IIP compilers are not in a position to do this initially because the deflation variable may take on non-positive values, and they have to assess the impact of removing these values and outliers by analyzing the whole range of central tendency measures first. The $5 \%$ exclusion threshold is in a strict sense arbitrary but the purpose is to eliminate the effect of outliers, which particularly in small datasets can influence the parameter estimates. The exclusion threshold will depend on the characteristics of the individual datasets.
} 
Table 2: Central tendency measures for valuation multiples

\begin{tabular}{|c|c|c|c|c|}
\hline Measure & Formula & Excluded data & Advantages & Disadvantages \\
\hline Total summation & $\frac{V_{i}}{X_{i}}=\sum_{j=1}^{n} V_{j}\left(\sum_{j=1}^{n} X_{j}\right)^{-1}$ & None & $\begin{array}{l}\text { - Takes all observations into account } \\
\text { - The summation mitigates the effect } \\
\text { of unusual company-specific events }\end{array}$ & $\begin{array}{l}\text { - The result may be dominated by a few } \\
\text { large companies, which are not } \\
\text { necessarily representative for unlisted } \\
\text { companies }\end{array}$ \\
\hline Positive summation & $\frac{V_{i}}{X_{i}}=\sum_{j=1}^{n} V_{j}\left(\sum_{j=1}^{n} X_{j}\right)^{-1}$ & $\begin{array}{l}\text { Listed companies } \\
\text { where } X_{j} \leq 0\end{array}$ & $\begin{array}{l}\text { - The summation mitigates the effect } \\
\text { of unusual company-specific events }\end{array}$ & $\begin{array}{l}\text { - The result may be dominated by a few } \\
\text { large companies, which are not } \\
\text { necessarily representative for unlisted } \\
\text { companies } \\
\text { - Does not use information about } \\
\text { companies where } X_{i} \leq 0\end{array}$ \\
\hline Arithmetic mean & $\frac{V_{i}}{X_{i}}=\frac{1}{n} \sum_{j=1}^{n}\left(V_{j}\left(X_{j}\right)^{-1}\right)$ & $\begin{array}{l}\text { Listed companies } \\
\text { where } X_{j} \leq 0 \text { plus } \\
\text { top } 5 \% \text { and bottom } \\
5 \% \text { of multiples }\end{array}$ & $\begin{array}{l}\text { - The result will not be dominated by a } \\
\text { few large companies }\end{array}$ & $\begin{array}{l}\text { The result may be dominated by } \\
\text { relatively few small companies } \\
\text { experiencing unusual events } \\
\text { - Does not use information about } \\
\text { companies where } X_{j} \leq 0\end{array}$ \\
\hline Weighted mean & $\frac{V_{i}}{X_{i}}=\sum_{j=1}^{n}\left(V_{j}^{2}\left(X_{j} \sum_{j=1}^{n} V_{j}\right)^{-1}\right)$ & $\begin{array}{l}\text { Listed companies } \\
\text { where } X_{j} \leq 0 \text { plus } \\
\text { top } 5 \% \text { and bottom } \\
5 \% \text { of multiples }\end{array}$ & $\begin{array}{l}\text { - The result will not be dominated by } \\
\text { relatively few small companies } \\
\text { experiencing unusual events }\end{array}$ & $\begin{array}{l}\text { - The result may be dominated by a few } \\
\text { large companies, which are not } \\
\text { necessarily representative for unlisted } \\
\text { companies } \\
\text { - Does not use information about } \\
\text { companies where } X_{j} \leq 0\end{array}$ \\
\hline Median & & $\begin{array}{l}\text { Listed companies } \\
\text { where } X_{j} \leq 0\end{array}$ & $\begin{array}{l}\text { - Less affected by the skewness in data } \\
\text { (distribution of multiples is typically } \\
\text { right-skewed as the P/E ratio is only } \\
\text { defined for companies with positive } \\
\text { earnings) }\end{array}$ & $\begin{array}{l}\text { - If the distribution of multiples for } \\
\text { unlisted companies is also right- } \\
\text { skewed, the result may be } \\
\text { underestimated } \\
\text { - Does not use information about } \\
\text { companies where } X_{j} \leq 0\end{array}$ \\
\hline
\end{tabular}

Note: $\mathrm{V}$ denotes market value of equity or EV; $\mathrm{X}$ earnings or book value; $\mathrm{i}$ unlisted companies; $\mathrm{j}$ listed companies in the peer group. In this study, a $5 \%$ exclusion threshold is used; the appropriate threshold depends on the specific dataset. 


\section{BOX 2: MODEL EVALUATION}

When evaluating the quality of the OLS regressions, $\mathrm{R}^{2}$ is often used as a measure for a model's goodness-of-fit. However, $\mathrm{R}^{2}$ as a model evaluation measure should be interpreted with caution in the presence of scale effects in the data because $\mathrm{R}^{2}$ will be heavily affected by extreme observations. Brown, Lo, and Lys (1999) show that $\mathrm{R}^{2}$ is upward biased when scale effects are present. Thus, $\mathrm{R}^{2}$ values should not be used to make comparisons over time and across samples. Moreover, it is important to keep in mind that $\mathrm{R}^{2}$ values of OLS models with and without a constant term cannot be compared directly.

Since neither scale effects nor multicollinearity can be directly detected in regression diagnostics, it is important to assess the plausibility of the parameter estimates. For instance, if earnings or book value turn out to have significantly negative parameter estimates, it is likely to be the result of multicollinearity.

The validity of central tendency measures for valuation multiples can be evaluated by analyzing the distribution of the multiples. The lower the standard deviation and skewness are, the more robust the measure is for valuation of equity. Another way to check the robustness of multiples is to compare different central tendency measures. A low dispersion indicates consistency in multiples.

Based on the above evaluation tools, it is possible to come up with a recommendation for a valuation model, which can be applied to unlisted direct investment equity. However, it has to be kept in mind that IIP compilers usually collect data on unlisted direct investment equity directly from companies, and in the compilation of macroeconomic statistics, the response burden has to be taken into account. Generally, it will make sense to stick to variables which are already collected for IIP or balance of payments (BOP) purposes or are within the companies' own business needs. If other variables improve the valuation models significantly, it will have to be assessed how costly it is for reporters to supply this information.

Even if $\mathrm{R}^{2}$ is not perfect, or the standard deviation of the multiples is significant, a model may still be useful. The model is going to be applied to macroeconomic statistics and will not be used for company-specific analyses. As long as there is no systematic bias between the unlisted companies and their peer group, the aggregation process will eliminate or significantly reduce random companylevel estimation errors. Therefore, it is recommended that the results are published as aggregates and not in too detailed breakdowns. 


\section{Data}

The estimation of the empirical valuation models in this study will be based on data for listed companies and then subsequently applied to unlisted equity. ${ }^{24}$ Alternatively, data for traded unlisted companies could have been used. ${ }^{25}$ These data would seem to be readily transferable to other unlisted companies since there would be no need to adjust for characteristics that are specific to unlisted equity, such as marketability discounts. There are, however, two reasons for not taking this route. First, a transaction price may be representative for only a short period as market and corporations' conditions constantly change and since untraded equity almost per definition are not traded or traded very infrequently, recent transactions prices for unlisted companies rarely exist, and such a approach is therefore not generally applicable. Second, the models would typically have to be based on a small number of observations since only a limited number of such transactions are observed in the BOP due to limited trading activity for unlisted equity. ${ }^{26}$

The empirical test is limited to only one dataset in order to eliminate valuation issues arising from the use of varying datasets. All estimations are based on data from Bureau van Dijk's ODIN Database, which contains information on all public and private limited companies in Denmark, Finland, Norway, and Sweden. ${ }^{27}$ The database contains accounting data for the last ten years for all companies, except Danish, where only data from the last five years are available due to legislative protection of company data. There are a total of 1,027 listed companies in the database. Results for 2006 are presented in this study while data for the period 2002-05 are used to check for model consistency.

Even though the models only are applied to the Danish IIP, data for a total of four Nordic countries are used to make the estimations. The reason is that the depth in the Danish

\footnotetext{
${ }^{24}$ An in-depth analysis of the model assumptions and their relation to the data is provided in Annex 3.

${ }^{25}$ The purpose of this section is solely to describe the reasons for the choice of dataset and not to address the differences between the valuation of listed and unlisted equity, which are discussed in Section 2C.

${ }^{26}$ This would be the case for Denmark, and it could be argued that consequently Denmark is not a good choice for this study. However, many countries record even fewer transactions than Denmark, which has a very open economy, so this issue will indeed be relevant to a number of compilers. According to UNCTAD's FDI database, Denmark is number 20 on the list of countries with the highest stock of inward FDI at end-2007.

${ }^{27}$ Data for financial institutions and insurance companies are not included in this database.
} 
stock market is limited, especially at the industry group level, and by including data from markets similar to the Danish stock market, the estimations will be based on a larger number of observations. In broad terms, business potentials and risks are comparable in the four countries, and there are no capital restrictions for investors in these countries. Remaining country-specific differences such as earnings perspectives, risks, regulations, taxation, and accounting principles are picked up by a country dummy variable, distinguishing between Denmark on one side and the other Nordic countries on the other side.

The Bureau van Dijk database contains a large number of variables for each company. The list of variables is reduced to only include theoretically well-founded variables related to earnings potential and risk. The variable concerning ownership is included in the gross variable list to make it possible to test whether companies with a few large investors are valued higher than other companies, cf. the discussion of the value of control premium in Section 2C. Also, as mentioned earlier, since liquidity is likely to affect market value, a trading volume variable is included. The number of subsidiaries is included because it may affect the earnings potential while company age can be regarded as a risk measure. ${ }^{28}$ In line with the Ohlson (1995) framework, a measure for book value is also included; specifically, OFBV is chosen because it is a well-defined concept that is also recommended in the BPM6.

Table 3: List of quantitative variables in the final dataset

\begin{tabular}{lll}
\hline Name & Description & Unit \\
\hline MVE & Total market value of equity at sample year-end & EUR million \\
OFBV & Own funds at book value at sample year-end & EUR million \\
EARNS & P/L before taxes in sample year & EUR million \\
EV & Enterprise value at sample year-end & EUR million \\
EBIT & Earnings before interest and taxes in sample year & EUR million \\
REVENUE & Revenue in sample year & EUR million \\
VOL & Equity trading volume in December of sample year & EUR million \\
HOLD & Largest owner's share of total equity at sample year-end & Per cent \\
SUBS & Number of recorded subsidiaries at sample year-end & Raw number \\
AGE & Time from incorporation to sample year & Raw number \\
\hline
\end{tabular}

\footnotetext{
${ }^{28}$ The hypothesis would be that newly-started companies run a larger risk of default because they have not been fully established and have not gained experience operating beyond the start-up phase.
} 
The dataset is unbalanced since new companies are listed while other companies are delisted every year. This is a normal company-demographic issue all compilers are faced with. Furthermore, the detail level of the accounting data differs across companies. The final dataset for 2006 contains 682 companies where the basic variables, $M V E$ and $O F B V$, are available. When relevant data are missing, the company is dropped in that model estimation, so the number of observations varies across models. Descriptive statistics for the 2006 dataset are shown in Table 4.

Table 4: Descriptive statistics on the quantitative variables in the final dataset

\begin{tabular}{lrrrrr}
\hline Name & Observations & Mean & Std. deviation & Minimum & Maximum \\
\hline MVE & 682 & $1,042.7$ & $4,052.3$ & 0.3 & $63,388.1$ \\
OFBV & 682 & 348.8 & $1,196.0$ & -3.3 & $11,124.1$ \\
EARNS & 681 & 72.0 & 422.8 & -637.0 & $7,404.0$ \\
EV & 623 & $1,259.3$ & $4,904.0$ & -0.1 & $70,326.1$ \\
EBIT & 674 & 23.0 & 171.1 & -132.1 & $2,937.0$ \\
REVENUE & 619 & 204.4 & $1,599.3$ & 0.0 & $32,651.0$ \\
VOL & 654 & $15,872.7$ & $101,718.7$ & 0.0 & $2,172,892.0$ \\
HOLD & 682 & 28.4 & 19.9 & 0.1 & 90.1 \\
SUBS & 682 & 26.7 & 50.5 & 0.0 & 421.0 \\
AGE & 680 & 26.4 & 25.7 & 0.0 & 110.0 \\
\hline Note: Variable definitions and units can be found in Table 3 & & &
\end{tabular}

Source: Calculations based on data from Bureau van Dijk's ODIN Database

All independent variables in the equity valuation models are positively correlated with market capitalization, and the same pattern is seen in the EV models (cf. Annex 4). The positive relationships are in line with expectations. Higher values of the independent variables should in theory increase the value of a company. However, the correlation tables also reveal that multicollinearity potentially is an issue in the multi-factor models. The correlation between OFBV and the earnings measures is at the borderline of the 0.7 rule-ofthumb threshold for multicollinearity. This may lead to a distortion of the parameter estimates if both variables are included in the valuation models.

In addition to the quantitative variables, the dataset contains three qualitative variables; a country variable, a NACE rev. 1.1 industry classification variable, and a variable 
controlling for companies included in the main stock market index. ${ }^{29}$ It is desirable to use a detailed industry classification as the peer group variable because potential earnings and risks differ across industries. However, even though data for four Nordic countries are used rather than just Danish data, the estimated valuation models would be based on a small number of observations if the most detailed industry classification was used. Consequently, the 11industry group breakdown recommendation from the Banque de France and Eurostat (2004) European Test Exercise is used as a starting point.

Table 5: List of qualitative variables in the final dataset

\begin{tabular}{|c|c|c|c|c|c|}
\hline Variable & Value & Description & NACE code & Frequency & Percent \\
\hline \multirow{4}{*}{ DK: } & 1 & Denmark & - & 103 & 15.1 \\
\hline & 0 & Finland & - & 124 & 18.2 \\
\hline & 0 & Norway & - & 113 & 16.6 \\
\hline & 0 & Sweden & - & 342 & 50.2 \\
\hline \multirow[t]{2}{*}{ Index: } & 1 & Included in main stock market index & - & 66 & 9.7 \\
\hline & 0 & $\begin{array}{l}\text { Not included in main stock market } \\
\text { index }\end{array}$ & - & 616 & 90.3 \\
\hline \multirow[t]{11}{*}{ Industry: } & 1 & $\begin{array}{l}\text { Information and communication } \\
\text { technology (ICT) activities }\end{array}$ & $\begin{array}{l}30,313,32,332,333 \\
642,7133,72\end{array}$ & 103 & 15.1 \\
\hline & 2 & Mining/energy & $\mathrm{C}+\mathrm{E}$ & 18 & 2.6 \\
\hline & 2 & Manufacturing (non-ICT) & $\begin{array}{l}\text { D (except 30, 313, 32, } \\
332,333)\end{array}$ & 119 & 17.5 \\
\hline & 2 & Construction & $\mathrm{F}$ & 7 & 1.0 \\
\hline & 3 & Trade & G & 51 & 7.5 \\
\hline & 3 & $\begin{array}{l}\text { Hotel/restaurants/transports/ } \\
\text { communication (non-ICT) }\end{array}$ & $\mathrm{H}+\mathrm{I}$ (except 642) & 36 & 5.3 \\
\hline & 4 & Financial intermediation & 65 & 46 & 6.7 \\
\hline & 4 & Insurance & 66 & 0 & 0.0 \\
\hline & 4 & Financial and insurance auxiliaries & 67 & 6 & 0.9 \\
\hline & 5 & $\begin{array}{l}\text { Real estate/non-financial services } \\
\text { (non-ICT/non-holdings)/others }\end{array}$ & $\begin{array}{l}\text { K (except } 7133,72 \\
7415)+ \text { others }\end{array}$ & 157 & 23.0 \\
\hline & 6 & Holdings & 7415 & 139 & 20.4 \\
\hline
\end{tabular}

Source: Calculations based on data from Bureau van Dijk's ODIN Database

\footnotetext{
${ }^{29}$ In this study, a main stock market index is defined as OMXC20 (Denmark), OMXH25 (Finland), OBX (Norway), and OMXS30 (Sweden).
} 
Table 5 reveals that some of the 11 industry groups used in the European Test Exercise only include a few companies in the case of the Nordic dataset, meaning that a single outlier could significantly affect the parameter estimates. Therefore, the industry group principle is maintained but some of the industry groups are combined, resulting in a total of six groups as indicated in the value column (the second column). The country variable will be treated as a single dummy variable, where Danish companies are assigned the value 1 and all other companies zero. Naturally, the stock index inclusion variable is also treated as a dummy variable. Additional data considerations are described in Box 3.

\section{BOX 3: PRACTICAL DATA CONSIDERATIONS}

A practical issue regarding input data is that the closing dates for the accounts vary across companies. Even though most companies close their accounts at the end of the of Gregorian calendar year, approximately $9 \%$ of the companies have a different account date. In principle, all stock variables should be recorded at the exact same point in time. These estimations can be done by using linear interpolation for positions between two accounting periods. However, this is a time-consuming process, and it would only affect a limited number of observations. Consequently, in order to avoid the transformations, it is assumed that stock variables do not change until the end of the Gregorian calendar year. If a significant company-specific event such as bankruptcy occurs, the compiler should of course take this into account.

A second consideration is that the length of the accounting year differs across companies. As stated above, most companies follow the Gregorian calendar year, which means that the flow variables such as earnings and revenue are measured for a 12-month period. However, different circumstances may lead to an accounting period longer or shorter than 12 months. In order to avoid biased estimates, data are prorated so all flow variables represent a 12-month period.

A third consideration is companies with dual share classes. In principle, the equity should be treated differently since prices differ. However, due to the small pricing differences in the Nordic countries documented by Nenova (2003), companies with dual share classes are included as one observation in the dataset with the most traded share class as indicator for market price. 


\section{EMpirical Modeling of Market VAlue Estimates}

Robustness and reliability are the two basic criteria when deciding on the appropriate valuation method and estimation technique for the valuation of unlisted direct investment equity. First, the method should be robust in the sense that applying different but typical estimation techniques should generate similar market value estimates; this criterion ensures that excessive bilateral asymmetries are avoided. Second, the method has to produce reliable market value estimates.

The robustness test can be regarded as the first step in the testing as robustness with respect to the recommended estimation techniques is a necessary, but not sufficient condition for reliable market value estimations. If the estimates differ depending on the estimation technique, it can clearly be concluded that at least some of the estimates would not be reliable.

\section{A. Estimation of Regression Models}

The natural starting point for the estimation of valuation models is the regression approach presented in Equation 3.1 because this model gives the best overall data fit in the absence of multicollinearity and scale effects ${ }^{30}$, a liquidity variable can be included directly, and the independent variables to be included in the estimations do not have a lower bound of zero.

Regression models are estimated jointly and for each of the six industry groups with different combinations of independent variables, cf. Table $6 .{ }^{31}$ The first model includes earnings and two liquidity variables as independent variables and can be regarded as a variant of the $\mathrm{P} / \mathrm{E}$ valuation method. The second model is based on the $\mathrm{P} / \mathrm{B}$ valuation method while the third model includes both earnings and book value as suggested in the Ohlson (1995) framework. The fourth and last model is also a multi-factor model, but it is estimated with $\mathrm{EV}$ as the dependent variable rather than market value of equity.

\footnotetext{
${ }^{30}$ Table 4, which displays the descriptive statistics of the variables in the dataset, reveals that scale differences are present, but a plausibility check of the parameter estimates has to be made in order to assess if the regression models are affected by scale effects.

31 The practical considerations and the model selection procedures are described in detail in Annex 4.
} 
Table 6: Regression models on market value of equity and EV

\begin{tabular}{|c|c|c|c|c|c|c|c|}
\hline & All industries & Group 1 & Group 2 & Group 3 & Group 4 & Group 5 & Group 6 \\
\hline & \multicolumn{7}{|c|}{ Earnings model on market value of equity } \\
\hline EARNS & $* 5.27$ & 4.17 & $* 6.94$ & 4.27 & $* * * 3.88$ & $* * * 22.34$ & 0.37 \\
\hline VOL & $* 0.01$ & $6.64 \mathrm{E}-02$ & $1.62 \mathrm{E}-02$ & $1.50 \mathrm{E}-03$ & $1.35 \mathrm{E}-02$ & $3.32 \mathrm{E}-03$ & $3.16 \mathrm{E}-02$ \\
\hline INDEX & $* * * 3545.80$ & 5018.00 & $* * * 3134.84$ & 2508.87 & $* * 1216.07$ & 1413.83 & $* * * 3368.76$ \\
\hline Observations & 653 & 96 & 142 & 85 & 52 & 146 & 132 \\
\hline \multirow[t]{2}{*}{ Adjusted $\mathrm{R}^{2}$} & 0.74 & 0.96 & 0.78 & 0.83 & 0.88 & 0.95 & 0.77 \\
\hline & \multicolumn{7}{|c|}{ OFBV model on market value of equity } \\
\hline OFBV & $* * * 1.96$ & 1.74 & 1.35 & $* * * 1.47$ & $* * * 0.72$ & 3.42 & 0.92 \\
\hline VOL & $* * * 1.15 \mathrm{E}-02$ & $8.72 \mathrm{E}-02$ & $2.32 \mathrm{E}-02$ & $2.14 \mathrm{E}-03$ & 7.04E-03 & $2.73 \mathrm{E}-03$ & $2.11 \mathrm{E}-02$ \\
\hline INDEX & $* * 1874.15$ & 617.68 & *2106.30 & 358.07 & $* * 1533.05$ & 3379.48 & $* * * 2554.19$ \\
\hline Observations & 654 & 97 & 142 & 85 & 52 & 146 & 132 \\
\hline \multirow[t]{2}{*}{ Adjusted $\mathrm{R}^{2}$} & 0.70 & 0.93 & 0.76 & 0.96 & 0.91 & 0.80 & 0.80 \\
\hline & \multicolumn{7}{|c|}{ Multi-factor model on market value of equity } \\
\hline EARNS & 3.81 & 4.95 & 5.33 & - & - & $* * * 22.34$ & - \\
\hline OFBV & $* 1.09$ & 2.55 & 0.98 & $* * * 1.47$ & $* * * 0.72$ & - & 0.92 \\
\hline VOL & $* 1.08 \mathrm{E}-02$ & 4.91E-03 & $1.08 \mathrm{E}-02$ & $2.14 \mathrm{E}-03$ & 7.04E-03 & $3.32 \mathrm{E}-03$ & $2.11 \mathrm{E}-02$ \\
\hline INDEX & $* * 1892.93$ & 1046.44 & $* 1666.25$ & 358.07 & $* * 1533.05$ & 1413.83 & $* * * 2554.19$ \\
\hline Observations & 653 & 96 & 142 & 85 & 52 & 146 & 132 \\
\hline \multirow[t]{2}{*}{ Adjusted $\mathrm{R}^{2}$} & 0.78 & 0.98 & 0.85 & 0.95 & 0.91 & 0.95 & 0.80 \\
\hline & \multicolumn{7}{|c|}{ Multi-factor model on EV } \\
\hline EBIT & 9.38 & 16.40 & - & 1.78 & - & - & 14.87 \\
\hline OFBV & $* * 1.92$ & $* * 2.19$ & $* 2.03$ & $* * * 2.20$ & 1.08 & 3.89 & 1.06 \\
\hline VOL & $* * 1.23 \mathrm{E}-02$ & $4.07 \mathrm{E}-03$ & $2.90 \mathrm{E}-02$ & $2.83 \mathrm{E}-03$ & $8.27 \mathrm{E}-03$ & $4.40 \mathrm{E}-03$ & $2.61 \mathrm{E}-02$ \\
\hline INDEX & $* * 2367.41$ & - & $* 2688.50$ & - & 1779.90 & 2702.83 & 3001.99 \\
\hline Observations & 599 & 94 & 137 & 83 & 45 & 136 & 104 \\
\hline Adjusted $\mathrm{R}^{2}$ & 0.83 & 1.00 & 0.82 & 0.98 & 0.80 & 0.83 & 0.78 \\
\hline
\end{tabular}

The estimation results show that the parameter estimates for all four models vary considerably across industry groups, indicating the need to estimate models based on industry groupings. The joint industry models including earnings and OFBV, respectively, display positive and significant parameter estimates as expected. Ohlson (1995) suggests that earnings and OFBV have complementary prediction power. This hypothesis is confirmed by 
the results presented in Table 7, showing that the adjusted $R^{2}$ increases by 9.4 percentage points when earnings are added to a valuation model with OFBV as the only independent variable. Similarly, the incremental effect is 13.6 percentage points when OFBV is added to a single-factor earnings valuation model. ${ }^{32}$

Table 7: Incremental effects on adjusted $R^{2}$ of adding variables to the regression models

\begin{tabular}{lccccccccr}
\hline Variable & OFBV & EARNS & VOL & HOLD & SUBS & AGE & INDEX & DK & Average \\
\hline OFBV & - & 0.136 & 0.360 & 0.448 & 0.452 & 0.542 & 0.312 & 0.601 & 0.407 \\
EARNS & 0.094 & - & 0.367 & 0.434 & 0.426 & 0.499 & 0.332 & 0.559 & 0.387 \\
VOL & 0.069 & 0.120 & - & 0.229 & 0.240 & 0.281 & 0.183 & 0.306 & 0.204 \\
HOLD & 0.009 & 0.038 & 0.086 & - & 0.060 & 0.127 & 0.013 & 0.165 & 0.071 \\
SUB & 0.001 & 0.017 & 0.083 & 0.047 & - & 0.106 & 0.022 & 0.149 & 0.061 \\
AGE & 0.002 & 0.001 & 0.036 & 0.025 & 0.017 & - & 0.016 & 0.065 & 0.023 \\
INDEX & 0.012 & 0.075 & 0.178 & 0.152 & 0.174 & 0.257 & - & 0.302 & 0.164 \\
DK & -0.001 & -0.001 & -0.001 & 0.002 & -0.001 & 0.003 & 0.000 & - & 0.000 \\
\hline
\end{tabular}

Note: The table shows the incremental effect of the row variable on adjusted $R^{2}$ in the equity model, given the column variable Source: Calculations based on data from Bureau van Dijk's ODIN Database

The overall conclusion from the regression model estimations is that earnings, OFBV and liquidity have a positive impact on market value of equity/EV, which is in line with our expectations. However, a more detailed analysis of the results reveals that while the signs of the parameter estimates may in general match our expectations, the sizes are often not plausible. For instance, the earnings parameter estimate for holding companies (Industry group 6) in the earnings model on market value of equity is 0.37 . The economic interpretation of the estimate would be that unlisted holding companies will generate a return that equals the entire investment within 5 months under the assumptions that trailing earnings equal leading earnings, and that the companies pay out dividends corresponding to their earnings. Evidently, this is not plausible, and it is likely that the parameter estimates are affected by scale effects or multicollinearity, which is supported by the fact that correlation between the independent variables exceeds $90 \%$ at the industry group level in some of the models.

\footnotetext{
${ }^{32}$ The findings are in line with the studies of Collins, Maydew and Weiss (1997) and Francis and Schipper (1999) who find that OFBV and earnings have complementary effects on value relevance. From a theoretical point of view, it does make sense that earnings as well as the investment base, i.e. OFBV, contribute significantly to the valuation model.
} 
Another interesting observation is that the OFBV parameter estimate for the information and communication technology industry (ICT - Industry group 1) in the OFBV model on market value of equity is only half the size of the largest parameter estimate of this type of model. Since intangible assets are often substantial in the ICT industry, it is surprising that the OFBV parameter estimate for this industry is so low. Also, two industry groups display OFBV parameter estimates below 1, indicating that future earnings, excluding one-off sales of existing assets, will be negative, or that the assets are overvalued in the companies' accounts. It seems unrealistic that expected future earnings on an aggregate industry group level are negative, and the cautiousness principle in accounting would normally prevent an overvaluation of assets. For these reasons, the size of the parameter estimates is highly questionable.

For the multi-factor models, multicollinearity plays an even more important role as the independent variables will to a large extent convey the same information. It is seen that some of the multi-factor models at the industry group level only includes earnings or OFBV, but not both variables. The reason is that the inclusion of both variables led to negative parameter estimates. This is very likely caused by multicollinearity or omitted variables. Moreover, the sample sizes for the industry group models are quite small, and the robustness of the estimates will thus be lower.

Due to the problems described above, compilers are recommended only to use levelbased regression models with utmost caution. If the models are used, they should be estimated on a large number of observations to mitigate the effect of a few dominating companies. In addition, it is necessary to assess the plausibility of the parameter estimates before applying the model. 


\section{B. Estimation of Valuation Multiples}

The implausible parameter estimates in the regression models suggest that it could be useful to calculate central tendency measures for valuation multiples instead and apply these to unlisted direct investment equity. Table 8 contains central tendency measures for $\mathrm{P} / \mathrm{E}, \mathrm{P} / \mathrm{B}$ and EV/EBIT ratios broken down by the six industry groups. ${ }^{33}$ The general tendency is that the arithmetic mean is higher than the median, which indicates a right-skewed distribution of valuation multiples. ${ }^{34}$

The dispersion can be used as measure to assess the validity of the input factor as an indicator for market value. The lower the dispersion is, the better the indicator is. Thus, it can be concluded that OFBV is a better indicator for market value of equity than earnings. Similarly, EV/EBIT ratios are slightly more stable across estimation techniques than $\mathrm{P} / \mathrm{E}$ ratios.

For $\mathrm{P} / \mathrm{B}$ ratios, it can be seen that the total and the positive summation measures yield identical results when reported with one decimal. This is due to few and small companies with negative OFBV. Interestingly, unlike the $\mathrm{P} / \mathrm{E}$ ratios, the arithmetic mean is lower than the weighted mean. The reason for this difference can primarily be attributed to a few companies included in the main stock market indexes with above-average $\mathrm{P} / \mathrm{B}$ ratios. An explanation for this could be that companies included in the main stock indexes are normally traded at a premium because of their high liquidity, which would have a positive impact on the $\mathrm{P} / \mathrm{B}$ ratios. The general trend, however, excluding companies in the main stock indexes, is that companies with OFBV below EUR 200 million have higher and more dispersed P/B ratios than larger companies.

\footnotetext{
${ }^{33} \mathrm{EV} / \mathrm{B}$ ratios are not calculated because this valuation multiple does not have the same theoretical appeal as the EV/EBIT ratio that is often preferred to $\mathrm{P} / \mathrm{E}$ when there are differences in financial leverage across companies. Whereas both EV and EBIT refer to all providers of capital, OFBV only refers to shareholders' equity and thus matches market value of equity rather than EV.

${ }^{34}$ The distribution of multiples is typically right-skewed because, for instance, the P/E ratio is only defined for companies with positive earnings. This means that companies with earnings just above zero will display large $\mathrm{P} / \mathrm{E}$ ratios whereas $\mathrm{P} / \mathrm{E}$ ratios for companies with earnings just below zero would not be included with large negative values, but would be excluded from the distribution instead. However, negative values are included in the calculations according to the total summation measure, cf. Table 2.
} 
Table 8: Central tendency measures for $P / E, P / B$, and $E V / E B I T$ ratios

\begin{tabular}{|c|c|c|c|c|c|c|c|}
\hline & All industries & Group 1 & Group 2 & Group 3 & Group 4 & Group 5 & Group 6 \\
\hline & \multicolumn{7}{|c|}{ P/E ratios } \\
\hline Total summation & 14.5 & 14.6 & 19.6 & 8.3 & 7.8 & 27.1 & 10.3 \\
\hline Positive summation & 12.8 & 13.9 & 16.4 & 7.5 & 7.2 & 23.8 & 8.8 \\
\hline Arithmetic mean & 40.5 & 41.4 & 34.0 & 35.3 & 30.9 & 42.0 & 53.8 \\
\hline Weighted mean & 29.5 & 24.9 & 24.0 & 23.5 & 19.9 & 34.5 & 43.6 \\
\hline Median & 20.7 & 30.5 & 21.6 & 15.2 & 11.3 & 27.1 & 24.0 \\
\hline \multirow[t]{2}{*}{ Dispersion } & $216 \%$ & $198 \%$ & $107 \%$ & $371 \%$ & $329 \%$ & $76 \%$ & $511 \%$ \\
\hline & \multicolumn{7}{|c|}{$P / B$ ratios } \\
\hline Total summation & 3.0 & 4.5 & 2.7 & 2.1 & 1.4 & 4.2 & 3.0 \\
\hline Positive summation & 3.0 & 4.5 & 2.7 & 2.1 & 1.4 & 4.2 & 3.0 \\
\hline Arithmetic mean & 3.6 & 3.8 & 3.5 & 3.7 & 2.7 & 3.7 & 3.5 \\
\hline Weighted mean & 4.2 & 5.4 & 3.9 & 3.0 & 2.3 & 4.6 & 4.1 \\
\hline Median & 2.7 & 2.9 & 2.9 & 2.5 & 1.5 & 2.6 & 2.9 \\
\hline \multirow[t]{2}{*}{ Dispersion } & $56 \%$ & $86 \%$ & $44 \%$ & $76 \%$ & $93 \%$ & $77 \%$ & $41 \%$ \\
\hline & \multicolumn{7}{|c|}{ EV/EBIT ratios } \\
\hline Total summation & 55.9 & 32.1 & 87.7 & 21.5 & 20.6 & 79.2 & 186.5 \\
\hline Positive summation & 31.0 & 28.1 & 33.8 & 15.9 & 8.8 & 57.4 & 50.6 \\
\hline Arithmetic mean & 78.6 & 82.5 & 67.3 & 51.4 & 22.6 & 87.2 & 158.5 \\
\hline Weighted mean & 80.7 & 32.2 & 72.4 & 25.8 & 21.2 & 110.2 & 199.5 \\
\hline Median & 33.6 & 32.8 & 32.6 & 19.5 & 17.9 & 50.8 & 86.1 \\
\hline Dispersion & $160 \%$ & $194 \%$ & $169 \%$ & $223 \%$ & $157 \%$ & $117 \%$ & $294 \%$ \\
\hline
\end{tabular}

As central tendency measures produce similar results for $\mathrm{P} / \mathrm{B}$ ratios, it seems reasonable to estimate a regression model based on company-specific $\mathrm{P} / \mathrm{B}$ ratios in order to construct aggregate $\mathrm{P} / \mathrm{B}$ ratios that can be used to revalue unlisted direct investment equity. The advantage of this approach is that there is no need define the peer groups prior to the construction of ratios.

Table 9 shows the regression results for a model with $\mathrm{P} / \mathrm{B}$ ratios as the dependent variable, after the exclusion of companies with negative OFBV and the top and bottom 5\% $\mathrm{P} / \mathrm{B}$ ratios. The independent variables are those that are explicitly or implicitly mentioned in international statistical manuals. Trading volume and the main stock market index dummy variable reflect liquidity, and they both have a positive impact on $\mathrm{P} / \mathrm{B}$ ratios as expected even though the contribution from trading volume is insignificant, and the parameter estimate is 
low. ${ }^{35}$ Companies with OFBV less than EUR 200 million display significantly higher P/B ratios than companies with OFBV of EUR 200 million or more, and Danish companies have slightly lower average P/B ratios than companies from other Nordic countries. The dummy variable for Industry group 4 (primarily financial intermediation) is significant in a one-sided test, but in general, industry group differences are relatively small. The insignificance of most industry group dummy variables may be ascribed to the limited number of observations in each industry group. It is seen that the parameter estimate for the ICT industry (D_IND1) is positive, which indicates higher $\mathrm{P} / \mathrm{B}$ ratios. This is expected as intangible assets, which are not fully covered by the IFRS, are often substantial for companies in this industry group.

Table 9: Regression model with $P / B$ ratios as dependent variable

\begin{tabular}{lrrrrrr}
\hline Variable & Coef. & Std. Err. & t-value & \multicolumn{1}{c}{ P>t } & [95\% Conf. & Interval] \\
\hline Intercept & 2.86 & 0.33 & 8.73 & 0.00 & 2.21 & 3.50 \\
VOL & $3.69 \mathrm{E}-07$ & $9.84 \mathrm{E}-07$ & 0.38 & 0.71 & $-1.56 \mathrm{E}-06$ & $2.30 \mathrm{E}-06$ \\
Index & 1.04 & 0.42 & 2.48 & 0.01 & 0.22 & 1.86 \\
DK & -0.10 & 0.27 & -0.38 & 0.71 & -0.63 & 0.42 \\
OFBV $<200$ & 0.77 & 0.29 & 2.62 & 0.01 & 0.19 & 1.34 \\
D_IND1 & 0.08 & 0.34 & 0.25 & 0.80 & -0.57 & 0.74 \\
D_IND2 & -0.07 & 0.30 & -0.22 & 0.82 & -0.65 & 0.52 \\
D_IND3 & -0.26 & 0.34 & -0.74 & 0.46 & -0.93 & 0.42 \\
D_IND4 & -0.88 & 0.42 & -2.09 & 0.04 & -1.71 & -0.05 \\
D_IND5 & -0.10 & 0.30 & -0.33 & 0.74 & -0.69 & 0.49
\end{tabular}

\begin{tabular}{cc} 
Adjusted $\mathrm{R}^{2}$ & 0.01 \\
\hline
\end{tabular}

Note: Industry group dummy variables have been created with Industry group 6 as the reference group

Source: Calculations based on data from Bureau van Dijk's ODIN Database

On basis of the regression results, it is possible to construct $\mathrm{P} / \mathrm{B}$ ratios for unlisted equity. If trading volumes are assumed to be zero, there will be twelve different $\mathrm{P} / \mathrm{B}$ ratios, namely two ratios for each of the six industry groups depending on size of OFBV. It is important to keep in mind that the model has a low coefficient of determination, as measured by $\mathrm{R}^{2}$. The $\mathrm{P} / \mathrm{B}$ ratios vary significantly, and there is much unexplained variation in the

35 It may be argued that the illiquidity discount seems rather low. A listed Danish company outside the OMXC20 Index in Industry group 6 with OFBV larger than EUR 200 million and with average trading volume will have a $\mathrm{P} / \mathrm{B}$ ratio which is only $0.2 \%$ higher than an unlisted company with the same characteristics. However, companies in the OMXC20 Index are traded at a large premium, and the stock market index variable may also be regarded as a liquidity variable. Therefore, if the listed company in the example above had the same characteristics, but was included in the OMXC20 Index, the total liquidity premium would be $38 \%$. 
model. However, if there is no systematic bias between listed and unlisted equity not already included in the model, it will yield reliable market value approximations on an aggregate level when the law of large numbers gets into effect.

\section{Discussion of the Estimated Valuation Models}

The two basic criteria for deciding on the appropriate valuation method and estimation technique for the valuation of unlisted direct investment equity are i) the method should be robust, i.e. generate similar market value estimates, when applying different but typical estimation techniques; and ii) the method has to produce reliable market value estimates. If the estimates differ depending on the estimation technique, it can clearly be concluded that at least some of the estimates are not be reliable.

Whereas it is possible to test the robustness of a valuation method, it is considerably more difficult to test the reliability empirically. One reliability test could be to apply a model estimated on the basis of a BPM6-recommened method to unlisted equity that has been traded to check if the method is able to predict the transaction price. However, as mentioned in Section 3A, such a test would not be generally applicable because it will be limited to a only a small number of unlisted companies due to limited trading activity among these companies, and traded unlisted companies may have different characteristics than non-traded unlisted companies. Another reliability indicator would be to assess the prediction power of a model, i.e. $\mathrm{R}^{2}$ for regression models and dispersion in the central tendency measures. In the absence of scale effects, a high $\mathrm{R}^{2}$ would indicate high prediction power as would a low dispersion in valuation multiples. However, it would still be necessary to evaluate if these models sensibly can be applied to unlisted equity.

Since reliability itself cannot be tested directly, compilers would have to rely on a combination of the methods' robustness, their prediction power and their theoretical appeal in order to give a qualified reliability assessment. If the recommended valuation methods

produce robust results, are associated with high prediction power, and the underlying 
theoretical framework is well-founded ${ }^{36}$, the method would serve as a useful guideline for IIP compilers.

Consequently, the first step in the evaluation process would be to compare the robustness of the tested methods and to assess if some of the proposed estimation techniques, i.e. the regression approach and the central tendency measures, should be excluded. All empirical results have shown that regression models based on non-deflated accounting data cannot be recommended as the estimations are severely affected by multicollinearity and scale effects leading to large volatility in the estimates. Therefore, the direct level-based regression approach should generally not be used by compilers.

This leaves the central tendency measures as the preferred estimation technique for the relative valuation methods; $\mathrm{P} / \mathrm{E}, \mathrm{P} / \mathrm{B}$, and $\mathrm{EV} / \mathrm{EBIT}$. The empirical estimations clearly illustrate that the results for the models using the stock variable OFBV are more robust than for models with before-tax earnings or EBIT as the independent variable. The main reason for this is the high degree of volatility connected to a flow variable like earnings. This is illustrated by the fact that $37 \%$ of all companies in the sample display negative before-tax earnings, and yet their market value is positive, indicating an expected positive change in the future according to the DCF models.

The distribution of $\mathrm{P} / \mathrm{B}$ multiples is clearly also right-skewed, but its standard deviation as a proportion of the mean is considerably smaller than for the P/E and EV/EBIT multiples. The comparatively low variation in $\mathrm{P} / \mathrm{B}$ ratios indicates that $\mathrm{OFBV}$ is a better valuation predictor than earnings. In other words, P/B ratios are more robust, are better valuation indicators and thus produce more reliable market value estimates than the earnings multiples.

\footnotetext{
${ }^{36}$ As shown in Section 2 and Annex 1, all BPM6-recommended methods can be linked to the theory of equity valuation. For this reason, this section will primarily address the robustness of the methods as a quality indicator.
} 


\section{Application of Models to the DAnish International InVEstment Position}

In this section, the effects of applying the empirically estimated valuation models to the Danish IIP are illustrated. It is clear that the Danish IIP is heavily dependent on the choice of valuation method as well as estimation technique. ${ }^{37}$

Figure 1 shows the effects on the total market value of inward unlisted direct investment equity in the Danish IIP when the estimated P/E central tendency measures are applied. ${ }^{38}$ The results are highly sensitive to both the choice of estimation technique and treatment of negative positions. The total market value estimates of unlisted inward direct investment equity vary from EUR 54 billion to EUR 341 billion. In other words, the largest estimate among $\mathrm{P} / \mathrm{E}$ models is $530 \%$ higher than the smallest; a difference corresponding to $63 \%$ of the total liabilities in the official Danish IIP. The simple mean method produces the highest estimate because the distribution of $\mathrm{P} / \mathrm{E}$ ratios is highly right-skewed, and the arithmetic mean is heavily affected by a few relatively small companies.

A part of the variation in the results may be ascribed to differences in the treatment of negative equity positions. Since negative earnings can be significant for unlisted companies and are not dwarfed by the earnings of a few large-cap companies as seen for listed companies, the exclusion of negative positions leads to aggregate estimates, which are approximately 50\% larger than aggregate estimates including negative positions. As mentioned in Section 2C, BPM6 allows the inclusion of negative direct investment equity positions.

\footnotetext{
${ }^{37}$ Due to limited data availability, we will only apply the equity valuation models and not the EV models. The level-based regression models will not be applied either due to the obvious scale effects on the parameter estimates.

${ }^{38}$ The data cannot be found directly in the published figures in the Danish IIP since the published tables do not contain a split between listed and unlisted equity. Moreover, financial institutions and insurance companies are not incorporated in our estimates since they are not included in the Bureau van Dijk ODIN Database.
} 
Figure 1: Value of inward unlisted direct investment equity in the Danish IIP (P/E models)

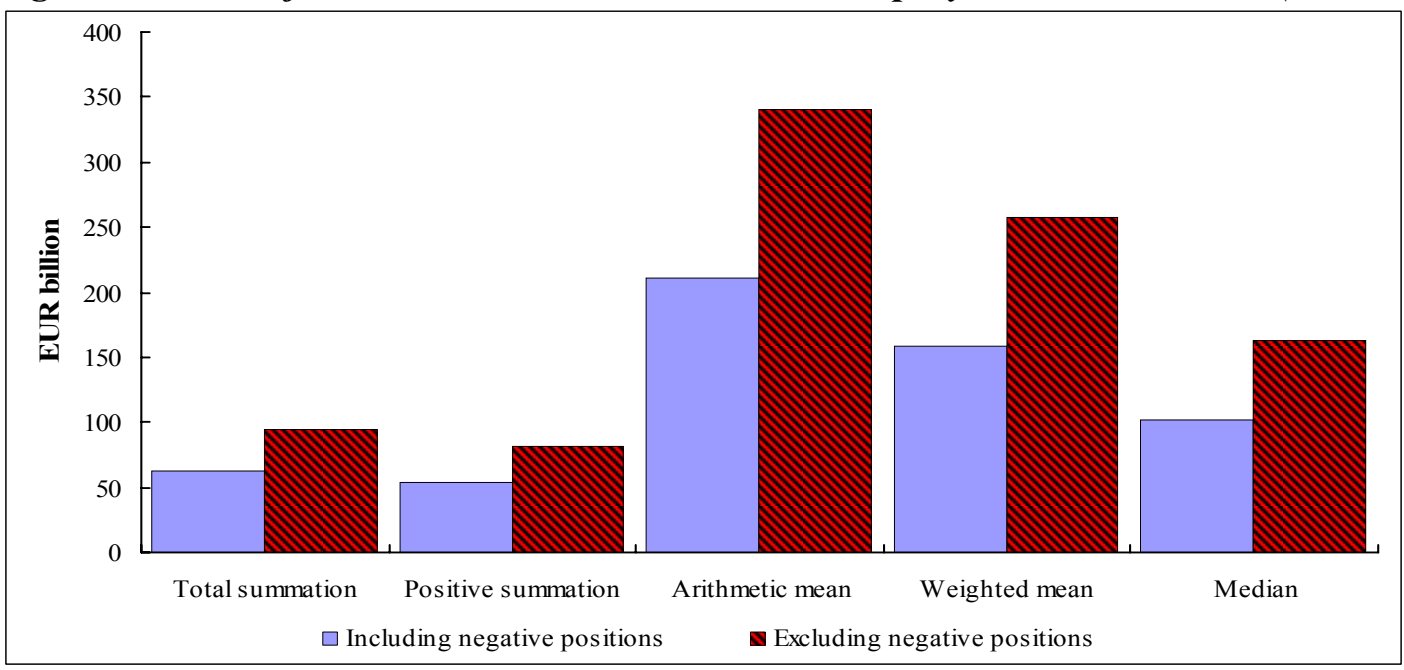

Source: Calculations based on data from Bureau van Dijk's ODIN Database

The consequences of implementing different $\mathrm{P} / \mathrm{B}$ models can be seen in Figure 2. The variation across estimation techniques is significantly lower than for the $\mathrm{P} / \mathrm{E}$ models, illustrating that $\mathrm{P} / \mathrm{B}$ models are more robust, better valuation predictors, and thus produce more reliable market value estimates than $\mathrm{P} / \mathrm{E}$ models, under the assumptions discussed in Section 4C. Total market value estimates of unlisted direct investment equity vary from EUR 130 billion to EUR 181 billion, the discrepancy corresponding to $11 \%$ of the total liabilities in the official Danish IIP. The difference of $40 \%$ between the highest and lowest direct investment estimates is considerably smaller than the difference of $530 \%$ observed for the $\mathrm{P} / \mathrm{E}$ models.

Also from Figure 2, it is clear that unadjusted $\mathrm{OFBV}^{39}$ generates significantly lower estimates than the relative valuation models, most likely because accounting standards only capture intangibles to a limited extent; OFBV may consequently underestimate market values. It is also clear that the arithmetic and weighted means produce the highest estimates. The arithmetic mean is upward biased because it is affected by the skewness in the distribution of $\mathrm{P} / \mathrm{B}$ ratios. Similarly, the weighted mean is upward biased because of the significant influence of a few large companies, which are included in major stock market indexes.

\footnotetext{
${ }^{39} \mathrm{OFBV}$ is included in the figure for illustrative purposes. In principle, it could be seen as a special case of the $\mathrm{P} / \mathrm{B}$ model where the ratio by definition equals 1 , which is exactly what makes it an absolute valuation model rather than a relative valuation model as the other P/B models presented in Figure 2.
} 
Figure 2: Value of inward unlisted direct investment equity in the Danish IIP (P/B models)

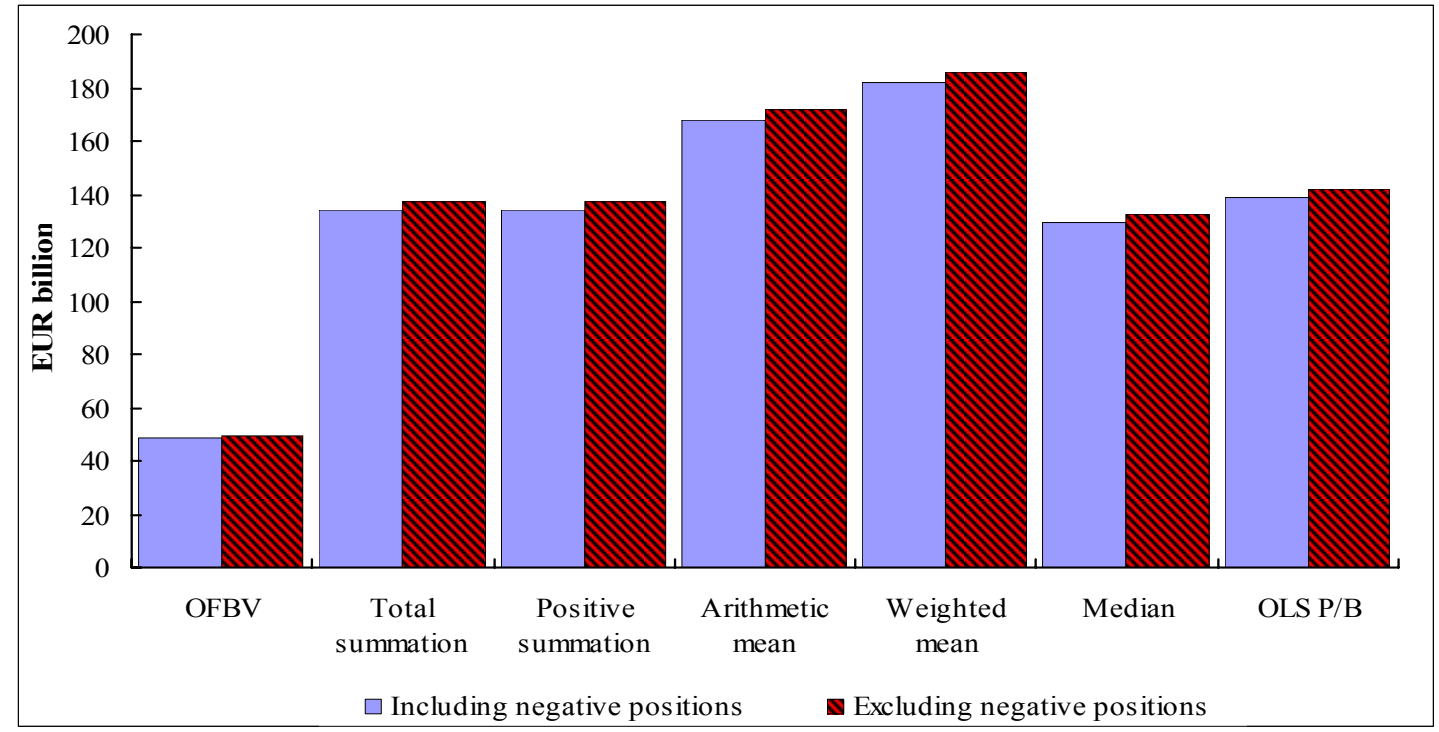

Source: Calculations based on data from Bureau van Dijk's ODIN Database

Another interesting finding is that it only makes a small difference whether negative direct investment equity positions are included or not even though almost $15 \%$ of the unlisted companies display negative OFBV. The reason is that there is a limit to how negative OFBV can get. Companies with large negative OFBV will be forced to restore the equity capital by authorities or creditors in order to stay in business. Consequently, the negative OFBV are relatively small compared to the positive OFBV. The conclusion is $\mathrm{P} / \mathrm{B}$ models are considerably more robust in terms of both estimation technique and the treatment of negative positions than the $\mathrm{P} / \mathrm{E}$ models.

Descriptive statistics for unlisted direct investment enterprises are presented in Annex 5, and a comparison with the figures for listed companies in the modeling dataset confirms that the unlisted companies generally are smaller than listed companies. If size plays a role in the valuation, and it is not taken into account in the valuation model, it will lead to biased results when the model is applied to unlisted equity. The regression model on $\mathrm{P} / \mathrm{B}$ ratios is the only model that includes size directly. Moreover, this model includes liquidity directly. For these reasons, in the case of Denmark, the regression model on $\mathrm{P} / \mathrm{B}$ ratios is preferred.

The next step is to analyze the overall effect of these findings by applying the chosen model to the Danish IIP. Since the model is only estimated for inward direct investment equity, it is for simplicity assumed that overall adjustment on the asset side is proportional to the adjustment on the liability side. 
Table 10 shows the consequences of implementing the valuation model to the Danish IIP. It can be seen that Denmark's total external assets would increase by $25 \%$ while the liabilities would increase by $21 \%$ compared to the official figures, which for unlisted direct investment equity are based on OFBV valuation. The asymmetric effect can be ascribed to the fact that Denmark has a positive net position in direct investment equity. This results in a significant improvement in Denmark's overall external financial position, which changes from a net liability position of DKK 17 billion to a net asset position of DKK 117 billion.

Table 10: Danish IIP end-2006 depending on valuation method for direct investment equity (amounts in DKK billion; percentage change in brackets)

\begin{tabular}{|c|c|c|c|c|}
\hline Valuation method & Financial instrument & Assets & Liabilities & Net assets \\
\hline \multirow[t]{3}{*}{ OFBV } & Direct investment equity & 589 & 496 & 93 \\
\hline & All other financial instruments & 2785 & 2895 & -110 \\
\hline & Total & 3374 & 3391 & -17 \\
\hline \multirow[t]{6}{*}{ Market value } & Direct investment equity & 1439 & 1212 & \\
\hline & & $(144 \%)$ & $(144 \%)$ & 227 \\
\hline & All other financial instruments & 2785 & 2895 & \\
\hline & & $(0 \%)$ & $(0 \%)$ & -110 \\
\hline & Total & 4224 & 4107 & \\
\hline & & $(25 \%)$ & $(21 \%)$ & 117 \\
\hline \multicolumn{5}{|c|}{$\begin{array}{l}\text { Note: The current official Danish IIP figures presented in the top part of the table are based on valuation according to the } \\
\text { OFBV method for unlisted direct investment equity. The IIP figures presented in the latter part of the table are based on } \\
\text { market value approximations according to the P/B regression model for unlisted direct investment equity. No market-value } \\
\text { adjustments are made for financial institutions and insurance companies. The total adjustment for outward direct investment } \\
\text { equity is assumed to be proportional to the adjustment on inward direct investment equity. The DKK/EUR exchange rate } \\
\text { was } 7.4560 \text { at end-2006. } \\
\text { Source. Calculations based on data from Bureau van Dijk's ODIN Database and official Danish IIP figures }\end{array}$} \\
\hline
\end{tabular}

Obviously, the results presented in Table 10 are based on the crude assumption that the adjustment factor on the assets is proportional to that on the liabilities. Nevertheless, the example clearly illustrates that moving from OFBV to other market value approximations can have a significant impact on IIP figures and the net financial position of a country published in official statistics. The net impact is likely to be large for countries with unbalanced direct investment equity positions, such as emerging markets, or for countries that observe considerable differences between $\mathrm{P} / \mathrm{B}$ ratios for inward and outward direct investment equity. 


\section{CONCLUSION AND RECOMMENDATIONS}

In response to the increasing importance of direct investment equity in a globalized world and the practical difficulties associated with approximating market values for this component, the BPM6 has introduced specific valuation guidelines with the aim of achieving reliable market value estimates and thereby minimize bilateral asymmetry.

All seven methods recommended in the BPM6 have their strengths and weaknesses. For the valuation of a certain company, one method may outperform the other methods while the same method will yield poor market value approximations for other companies. As an IIP compiler, it is essential to find the method or mix of methods that will provide the most reliable estimates at the aggregation level data are published on. ${ }^{40}$

Even though the empirical part of this study has been carried out with a special focus on practical issues related to the Danish IIP, it illustrates the importance and risks of using different methods and estimation techniques across different countries. The analysis clearly shows that OFBV is a more robust valuation indicator than earnings, which have proven to be highly volatile (cf. Figure 1). Another important point is that this work has shown that the choice of estimation technique plays a significant role, particularly for the earnings models. If IIP compilers apply valuation multiples to accounting data, it does make a significant difference how these multiples are calculated in practice (cf. Table 8). Consequently, compilers have to analyze the distribution of multiples and make comparisons to data for unlisted companies before choosing an estimation technique. If multiples seem to be robust, it is possible to estimate a regression model with the multiple as dependent variable since this variable has now been deflated for scale differences in data as done in the $\mathrm{P} / \mathrm{B}$ model presented in Table 9. Additionally, the regression approach has the advantage that it allows the direct inclusion of liquidity variables.

While the BPM6 provides improved guidance compared to the BPM5 by listing seven recommended methods for the valuation of unlisted direct investment equity, the empirical study reveals that the number of recommended methods and, equally important, the room for

\footnotetext{
${ }^{40}$ Annex 6 sums up the practical advice for the compilers given throughout this paper. It also provides an overview of the relations between the theory of equity valuation, the BPM6-recommended methods, and the empirical estimation of valuation models.
} 
interpretation within each method may need to be reduced over time. This should be done to enhance cross-country consistency in direct investment data and thereby increase international comparability. However, for this to be possible and to provide precise guidelines on how to deal with the remaining methods, studies similar to this one have to be carried out for other countries. It may turn out that there is a need for more than just one valuation method or a combination of methods depending on individual country circumstances.

The study has also shown that it is a time-consuming process to estimate valuation models. In principle, Danish compilers would need to estimate models for every single country in which Denmark has outward direct investment equity before they can revalue the asset side of the Danish IIP. For practical reasons, it is not realistic that every country can estimate country-specific models for every counterpart country on the outward side. Moreover, this study shows there is an evident risk that bilateral asymmetries would occur due the choice of estimation technique and input data. One way to i) lower the burden for IIP compilers, ii) reduce bilateral asymmetries, and iii) achieve better market value approximations is to establish a set-up that allows IIP compilers to share their experiences and valuation models with each other. For instance, if every country developed models for the valuation of inward direct investment equity and shared them with other IIP compilers, much progress could be made on some or all of the three goals. It is conceivable that the workload would be eased when IIP compilers only have to develop models for valuing inward direct investment equity. Even more, bilateral asymmetries would ceteris paribus be reduced if everybody uses the same model to value direct investment enterprises resident in a given country. Lastly, it can be argued that the quality of the estimates will be improved if the valuation models are being estimated by compilers with extensive knowledge about the specific country.

Naturally, there are a number of practical issues, on which countries need to agree if the models are to be shared and implemented worldwide. First, it is important to agree on the detail level of the industry breakdowns. Countries will typically compile IIP data with a certain industry breakdown, and it is likely to cause problems if different breakdowns are used for different countries. Moreover, this study has shown that the treatment of negative direct investment equity positions matters if the valuation indicator can take on negative 
values. For the same reason, it is preferred to use a valuation indicator, which rarely takes on negative values and in such cases only small values.

Another practical problem is the treatment of special purpose entities (SPEs). The valuation of such companies may be different from the valuation of regular companies. These companies are often established for tax purposes, and typically their main function is to own a subsidiary in another country in order to create a way to channel earnings through a country with favorable tax rates. One specific concern is that the value of inward direct investment should equal the value of outward direct investment for pass-through companies. However, this will not be the case if the parameter estimates in the valuation models vary across countries. One solution to this problem would be to share information on the valuation of pass-through companies between IIP compilers.

To promote consistency in estimates of bilateral direct investment positions, the IMF recommends the use of OFBV as the valuation principle for unlisted equity in the CDIS, and this symmetric valuation principle could give IIP compilers a valuable tool to detect bilateral asymmetries. The recommendation to use OFBV as valuation principle also is in line with this study's conclusion that $\mathrm{P} / \mathrm{B}$ ratios should be used to value unlisted direct investment equity. If $\mathrm{P} / \mathrm{B}$ models are estimated for all countries, the CDIS will be able to provide the necessary input data to approximate market values for direct investment equity in all participating IMF member states based on a consistent valuation principle. This will indeed be a valuable contribution to the analyses of globalization and the wealth of nations. 


\section{REFERENCES}

Barth, Mary E. and Sanjay Kallapur (1996), "The Effects of Cross-Sectional Scale Differencences in Empirical Accounting Research", Contemporary Accounting Research, v13 (2), pp. 527-567.

Brennan, Michael J., Tarun Chordia, and Avanidhar Subrahmanyam (1998), "Alternative factor specifications, security characteristics, and the cross-section of expected stock returns", Journal of Financial Economics, v49 (3), pp. 345-373.

Brown, Stephen, Kin Lo, and Thomas Lys (1999), "Use of $\mathrm{R}^{2}$ in Accounting Research: Measuring Changes in Value-Relevance over the Last Four Decades", Journal of Accounting and Economics, v28 (2), pp. 83-115.

Banque de France and Eurostat (2004), "The Valuation of unquoted shares: a European test exercise", Banque de France Bulletin Digest, No. 127, pp. 33-52.

Capcun, Vedran, Anne Cazavan-Jeny, Thomas Jeanjean and Lawrence A. Weiss (2007), "Transition to IFRS: Value Relevance and Earnings Management", unpublished working paper.

Christie, Andrew A. (1987), “On Cross-Sectional Analysis in Accounting Research", Journal of Accounting and Economics, v9 (3), pp. 231-258.

Collins, Daniel W., Edward L. Maydew and Ira S. Weiss (1997),'Changes in the valuerelevance of earnings and book values over the past forty years", Journal of Accounting and Economics, v24 (1), pp. 39-67.

Damodaran, Aswath (2002), “Investment Valuation”, $2^{\text {nd }}$ Edition, Wiley.

Damodaran, Aswath (2005a), "Marketability and Value: Measuring the Illiquidity Discount". Available at SSRN: http://ssrn.com/abstract=841484.

Damodaran, Aswath (2005b), "The Value of Control: Implications for Control Premia, Minority Discounts and Voting Share Differentials". Available at SSRN: http://ssrn.com/abstract=837405.

European Council, Council Regulation (EC) No 2223/96 of 25 June 1996 on the "European system of national and regional accounts in the Community (ESA95)".

Francis, Jennifer and Katherine Schipper (1999), "Have Financial Statements Lost Their Relevance?”, Journal of Accounting Research, v37 (2), pp. 319-352.

Gjerde, Oystein, Kjell Henry Knivsflå, and Frode Saettem (2007), "The Value-Relevance of Adopting IFRS: Evidence from 145 NGAAP Restatements". Available at SSRN: http://ssrn.com/abstract $=966080$ 
Hitchner, James R. (2006), "Financial Valuation: Applications and Models", 2 ${ }^{\text {nd }}$ Edition, Wiley.

International Monetary Fund (2008), "Balance of Payments and International Investment Position Manual, Sixth Edition (BPM6)".

Koeplin, John, Atulya Sarin, and Alan C. Shapiro (2000), "The Private Company Discount", Journal of Applied Corporate Finance, v12 (4), pp. 94-101.

Kozlow, Ralph (2002), "Valuing the Direct Investment Position in U.S. Economic Accounts", BOPCOM 00-16.

Levy Yeyati, Eduardo, Sergio L. Schmuckler, and Neeltje Van Horen (2006), "International Financial Integration through the Law of One Price", World Bank Policy Research Working Paper no. WPS3897.

Meitner, Mathias (2006), “The Market Approach to Comparable Company Valuation”, ZEW.

Nenova, Tatiana (2003). "The value of corporate voting rights and control: A cross-country analysis", Journal of Financial Economics, v68 (3), pp. 325-351.

Nguyen, Duong, Suchismita Mishra, Arun Prakash, and Dilip K. Ghosh (2007), "Liquidity and Asset Pricing under the Three-Moment CAPM Paradigm", Journal of Financial Research, v30 (3), pp. 379-398.

Ohlson, James A. (1995), "Earnings, Book Values, and Dividends in Equity Valuation", Contemporary Accounting Research, v11 (2), pp. 661-687.

Organisation for Economic Co-operation and Development (2008), "Benchmark Definition of Foreign Direct Investment, Fourth Edition".

Stowe, John D., Thomas R. Robinson, Jerald E. Pinto, and Dennis W. McLeavey (2002), "Analysis of Equity Investments: Valuation", AIMR.

Veira, Pablo J. Vazquez (2006), "Price-Levels Regressions: Scale Effect or Distribution Effect?” Available at SSRN: http://papers.ssrn.com/sol3/papers.cfm?abstract id=851025.

White, Halbert (1980), "A Heteroskedasticity-Consistent Covariance Matrix Estimator and a Direct Test for Heteroscedasticity”, Econometrica, v48 (4), pp. 817-838. 


\section{ANNEX 1: BPM6-RECOMMENDED VALUATION METHODS}

\section{(A) Recent Transaction Price}

The recent transaction method suggests that when unlisted equity has been traded recently, the transaction price can be used as the market price. However, conditions change, and it is recommended in the BPM6 that the transaction price be used to approximate market value for a maximum of one year without making adjustments due to changes in the corporation's position and general market conditions. Formally stated, the market value of company $i$ at time $t$ is then given by:

$$
V_{i t}=P T R S_{i \tau}\left(T S_{i t}\left(T R S_{i \tau}\right)^{-1}\right) \text {, }
$$

where PTRS denotes the total price of the shares traded in company $i$ at time $\tau$, which has to be within one year prior to time $t$. TS indicates the total number of shares in the company, and TRS equals the number of shares, which were traded at time $\tau$. The formula cannot be used directly if the company has initiated corporate actions such as large dividend payouts or stock splits since the transaction date.

The main advantage of this method is that it is easy to implement for equity, which has been traded. Furthermore, if the transaction is made between two independent parties, the transaction price, by definition, equals the market price at the time of the transaction.

On the other hand, market values can change rapidly with market conditions and the situation of a specific company. For instance, equity may be traded at a high price in case of a bidding war, but if the other parties taking part in the bidding process subsequently lose interest in the target company, this could lead to a significant reduction in the market value. Another problem is that a recent transaction price is often not available. The reason is that one of the principal characteristics of unlisted equity is that it is not traded on a regular basis. Otherwise, these companies would have been listed to ease liquidity constraints.

\section{(B) Net Asset Value}

According to this method, fair value of unlisted equity can be estimated as total assets at current value minus total liabilities (excluding equity) at market value. The appraisals can 
either be performed by knowledgeable management or independent auditors. The BPM6 directly mentions that intangible assets should be covered, but the OECD Benchmark Definition of Foreign Direct Investment, 4th Edition (BD4, paragraph 524) recognizes that it is often very difficult to estimate the value of these assets, and they may thus be excluded. ${ }^{41}$ Finally, the appraisals have to have been conducted within the last year.

The advantage of this method is that knowledgeable management and independent appraisers, who are close to the company, often have superior knowledge about the actual value of a company. They may even know how much potential buyers are willing to pay for the company, which would be a direct approximation of market value. Unlike macroapproach methods, this valuation technique also takes specific company details into account.

Nevertheless, the method has some weaknesses. Since the valuation is left to reporters, compilers do not exactly know how much effort company officials put into the valuation process or if it is done consistently across companies. Moreover, some companies may have an interest in providing incorrect values for reasons such as tax evasion, shareholder protection, fear that competitors will obtain the information, etc. The risk for misinterpretation of market value and the existence of potential protectionist incentives may lead to a mix of accurate and inaccurate data.

\section{(C1) Present Value of Earnings}

This method is based on the absolute valuation model where expected future earnings are discounted to get the present value or the fundamental value of a company. According to this method, the IIP compiler will have to find a way to forecast future earnings and to determine the appropriate discount rate by assessing risk factors. The market value of company $i$ at time $t$ is then given by:

$$
V_{i t}=\sum_{T=t+1}^{\infty} \frac{E_{i T}}{(1+r)^{T}}
$$

\footnotetext{
${ }^{41}$ Full consistency between international statistics manuals was one of the main objectives of the updates of the IMF's BPM6, OECD's BD4, and UN's System of National Accounts 2008. Thus, more detailed descriptions of certain aspects in other statistics manuals can be used by statistics compilers following the BPM6.
} 
where $E$ denotes earnings, and $r$ represents the discount factor, which is the sum of the riskfree interest rate and the risk premium. Equation A1.2 could in principle be rewritten to resemble the GGM in Equation 2.1 if it is assumed that the earnings growth rate is constant.

The main advantage of this method is that it uses the theoretically sound principle to determine fundamental value of equity by including estimates of future earnings. In a case where future earnings of a specific company are expected to differ significantly from past earnings, it becomes necessary to include such expectations to capture the effect on the market equivalent value.

The most important drawback is that it is extremely time-consuming to make reliable earnings forecasts, if possible at all, at a company level. It may be possible to come up with industry level estimates, but in that case, IIP compilers may as well draw on the relative valuation models since the overall market expectations are captured with these models. In addition, the absolute valuation models are used to estimate the fundamental value of an asset. Irrational exuberance and asset price bubbles are sometimes observed in the markets, and hence, the fundamental value does not always equal the market value. This can partly be ascribed to the fact that there is no general consensus among equity analysts about the fundamental value of a specific asset due to differences in expectations. Since the recommended valuation principle in international statistical manuals is market value or market value equivalents, in the absence of observed market prices, it is indeed problematic to estimate fundamental values rather than market value equivalents.

\section{(C2) Price to Earnings}

The price-to-earnings method is based on the relative valuation models. According to this method, $\mathrm{P} / \mathrm{E}$ ratios for listed companies can be calculated and applied to unlisted equity. Recognizing potential industry-specific differences, it is suggested that the ratios are calculated for industry groups in order to estimate across similar companies rather than calculating a common $\mathrm{P} / \mathrm{E}$ ratio to be applied to all companies. Formally, the market value of company $i$ at time $t$ may be calculated as: ${ }^{42}$

\footnotetext{
${ }^{42}$ The BPM6 does not give explicit guidelines for the calculation of valuation multiples. Section 3B provides a list of alternative estimation techniques.
} 


$$
V_{i t}=E_{i \tau}\left(\sum_{j=1}^{n} V_{j t}\left(\sum_{j=1}^{n} E_{j \tau}\right)^{-1}\right),
$$

where the subscript $j$ is used for listed companies in the peer group. The BPM6 does not precisely define the term earnings, denoted by $E$, but it is suggested excluding one-off factors as these may distort the calculations.

An important quality of the method is that it is fairly easy to implement. Furthermore, it uses actual market values rather than economic fundamentals such as expected earnings and interest rates in the estimations of fair value. In circumstances where the stock market seems to be out of line with economic fundamentals, the estimations will still be market value approximations. The LOOP, stating that similar assets must be traded at similar prices, is more likely to be hold than the principle that assets are traded at their fundamental value. The reason is that the estimation of fundamental value is more uncertain and subjective than the estimation of relative value.

A significant disadvantage is that the method, like other relative valuation methods, does not take individual company characteristics into account. If a specific company is expected to grow faster in the future than its peers, the method will not be able to catch this. ${ }^{43}$ Calculating PEG ratios on the company level could help, but this would be a very timeconsuming and uncertain process in the context of macroeconomic statistics where such calculations would often have to be made for thousands of companies. Another drawback is that the method assumes that $\mathrm{P} / \mathrm{E}$ ratios are identical for listed and unlisted equity. Even if IIP compilers are able to estimate illiquidity discounts ${ }^{44}$, they would still have to make sure that the accounting principles for listed and unlisted companies generate identical or at least nonbiased results. A potential and practical problem related to the accounting figures is that unlisted companies are more likely to make inappropriate use of transfer pricing than listed companies since the former are very often fully-owned subsidiaries.

\footnotetext{
43 Assuming that the peer group is defined by industry classification rather than expectations about future earnings.

${ }^{44}$ See Annex 2 for a detailed discussion on the treatment and estimation of illiquidity discounts.
} 


\section{(D) Price to Book Value}

The price-to-book value method is another variant, which is based on the relative valuation models. The underlying idea is that book values do not necessarily approximate market values well. To compensate for this, the method multiplies book value by a capitalization factor to estimate market value, similar to the $\mathrm{P} / \mathrm{E}$ model. The BPM6 suggests using $\mathrm{OFBV}^{45}$ as book value measure. The formula from Method C2 (Equation A1.3) can be reused with the exception that OFBV rather than earnings is used as the factor. ${ }^{46}$ The market value of company $i$ at time $t$ can thus be computed as:

$$
V_{i t}=B_{i \tau}\left(\sum_{j=1}^{n} V_{j t}\left(\sum_{j=1}^{n} B_{j \tau}\right)^{-1}\right) .
$$

Fundamentally, this method shares the same pros and cons as Method C2 on price to earnings. The only difference is that one method uses a flow variable (earnings) in the estimation of market value while the other uses a stock variable (book value). According to general theory of equity valuation, the value of a firm is defined as the present value of future earnings. Taking this view, it may seem more appealing to use earnings as input in the valuation model rather than book values. However, earnings are volatile and often negative while book values, being a stock variable, tend to be more stable, and they do, to some extent, include earnings because the accumulation of previous years' reinvested earnings are included in the book values. In addition to this, the book value can be seen as an indication of a company's net worth if it were to be liquidated. Thus, it is not clear that one approach is superior to the other. ${ }^{47}$

\footnotetext{
${ }^{45}$ See definition of OFBV under Method E.

46 The BPM6 also leaves it to compilers to determine precisely how to calculate adjustment factors for P/B valuation multiples.

47 Ohlson (1995) develops a framework, in which both earnings and book value are included in the valuation model. The idea is that equity value can be regarded as a function of current book value and future earnings instead of discounted expected returns only. Studies by Collins, Maydew, and Weiss (1997) and Francis and Schipper (1999) conclude that earnings and book value have complementary effects on equity value.
} 


\section{(E) Own Funds at Book Value (OFBV)}

The concept of OFBV is an attempt to standardize the term book value, which can be defined in multiple ways. The BPM6 (paragraph 7.16(e)) defines OFBV as "the value of the enterprise recorded in the books of the direct investment enterprise, as the sum of (i) paid-up capital (excluding any shares on issue that the enterprise holds in itself and including share premium accounts); (ii) all types of reserves identified as equity in the enterprise's balance sheet (including investment grants when accounting guidelines consider them company reserves); (iii) cumulated reinvested earnings; and (iv) holding gains or losses included in own funds in the accounts, whether as revaluation reserves or profits/losses." The closer the accounting principles follow the IFRS, the better is the approximation of market value because these standards require most assets to be revalued, at least, on an annual basis.

This approach has two apparent advantages. First of all, the definition is precise and easy to implement. Secondly, if all countries used this method, it would promote symmetric bilateral recording. ${ }^{48}$

However, the method also has drawbacks. Even though the IFRS goal is to approximate market values, there is still some scope for different approximations, especially with the valuation of intangibles that often can be a major component of the market value. Since many intangibles are excluded from the IFRS, book values may underestimate market values. On the other hand, experiences have shown that, for instance in times of distress, some financial firms have tended to recognize losses on loan portfolios slowly with the result that book values only are written down some time after a loss has been sustained. In such cases, book values may overestimate market values. In addition, the IFRS are still to be fully implemented in most countries.

\footnotetext{
${ }^{48}$ The statement of bilateral symmetry rests on the assumption that IIP compilers in both involved countries use OFBV measured by the same accounting standard and the same interpretation of this standard. Foreign-owned subsidiaries will often have a set of accounts drawn up according to local standards and another set based on the general accounting standard in the group. If all IIP compilers used the set of accounts drawn up according to the local standard in the country of the direct investment enterprise, bilateral symmetry within the OFBV framework would ceteris paribus be ensured.
} 


\section{(F) Apportioning Global Value}

According to the global value method, the market value of each of the companies in a listed international group can be found by prorating the overall market value from the stock exchange to the entities, which make up the entire group. Sales, net income, assets, or employment figures can be used as apportioning indicators. If IND denotes the indicator, $i$ an entity in a listed group, and $j$ the group, the market value of entity $i$ at time $t$ is given by:

$$
V_{i t}=I N D_{i \tau}\left(V_{j t}\left(I N D_{j \tau}\right)^{-1}\right) .
$$

This method has the advantage that market value approximations are in fact based on the actual market value of the group. Hence, fluctuations in market value due to changes in expectations about future earnings will be captured by the model. Besides, the practical implementation of the method is straightforward once the indicator data have been selected.

A clear disadvantage is that it is difficult to determine how to prorate the value of the entire group to a company within the group. If there is a sudden increase in the market value of the entire group, it may be the result of an expected increase in future earnings for a certain company in the group. It is likely to be difficult to find an indicator that will capture this effect. Furthermore, this is not a general method, which can be applied to all unlisted equity since many unlisted direct investment enterprises are not a part of a listed group. 


\section{AnNex 2: Issues Related PaRticularly to VAluation OF UNLISTED EQuity}

\section{Illiquidity Discounts}

When an investor decides to sell an asset, he will incur some trading costs. These costs are often referred to as "the cost of illiquidity" and consist of four components; the bid-ask spread, the price impact when buying or selling, the opportunity costs, and the commission (Damodaran, 2005a). In general, the trading costs will be low for frequently traded assets and high for infrequently traded assets because the bid-ask spread tends to narrow for frequently traded assets, for which there are many buyers and sellers. The illiquidity discount is, all other factors being equal, higher for unlisted equity than for traded listed equity due to differences in trading costs.

Given the existence of illiquidity discounts, the question is how these discounts should be treated according to international statistical manuals. The BPM6 does not mention liquidity considerations in any of the seven recommended methods. Nevertheless, the overall valuation principle is that market value equivalents should be estimated if market prices are not readily available. From this, it can be inferred that the illiquidity discounts on unlisted equity should be taken into account if they are significant. The European system of national and regional accounts in the Community (ESA 95, paragraph 7.54) explicitly mentions that unlisted equity must be valued with a reference to listed equity and adjusted for differences in liquidity. Similarly, the BD4 (paragraphs 521 and 525) points out that market capitalization ratios may be adjusted for differences in liquidity.

The methods for estimating illiquidity discounts suggested in the literature follow two different lines; whether it is important for the valuation that a company is listed or not. The difference can be illustrated by a simple multi-factor regression model:

$$
Y_{i}=\beta_{0}+\beta_{1} X_{1, i}+\beta_{2} X_{2, i}+\ldots .+\beta_{n-1} X_{n-1, i}+\beta_{n} D_{-} U_{N L I S T E D}+\varepsilon_{i}, \text { (A2.1) }
$$

where $Y_{i}$ is a replacement character for market value of the equity or EV of company $i$ and $\left[X_{1} ; X_{n-1}\right]$ represent the explanatory variables. The debate is on whether or not a dummy variable for marketability, D_UNLISTED, should be included. Stowe et al. (2002) argue that there both is an illiquidity discount and a marketability discount. The illiquidity discount 
takes into account the differences in the depths of the market for the specific company while the marketability discount is a dummy variable, which captures the difference in value that can solely be ascribed to whether or not equity is listed. Damodaran (2005a), on the other hand, argues that liquidity is in fact a continuum since all assets can be sold, and are thus liquid, if the seller is willing to accept a lower price for them. Both views agree that one of the $X$ variables in the valuation model should be a liquidity variable, but according to Damodaran the dummy variable should not be included. There are good arguments for and against both approaches. It makes sense that listed companies should ceteris paribus trade at a higher price than similar unlisted companies since they already are listed on an established platform, on which they can be traded efficiently. Conversely, if listed companies are not being traded, but are merely listed, it is an indication that the equity is no more liquid than unlisted equity.

If the dataset contains a variable distinguishing between listed and unlisted companies, it is easy to test if a dummy variable coefficient is significantly different from zero. In the relative valuation setup proposed in Methods C2 and D, however, there are only data for listed companies, so we have to rely on other studies to determine whether or not to include a marketability discount in addition to the illiquidity discount when estimating market value of unlisted equity. ${ }^{49}$

There are many empirical studies on the estimation of illiquidity discounts, and even though they all reach the same overall conclusion of significant discounts, there is no consensus on the size of it. Brennan, Chorida, and Schwartz (1998) find a negative relationship between trading volume and stock returns. This finding indicates that investors are willing to accept a lower return on highly liquid assets or stated differently, they are willing to pay a premium for liquidity. Nguyen, Mishra, Prakash, and Ghosh (2007) find a similar correlation between turnover ratios (trading volume/market value of equity) and expected returns. Interestingly, they also find that market capitalization and $\mathrm{P} / \mathrm{B}$ ratios do not

\footnotetext{
${ }^{49}$ Banque de France and Eurostat (2004) suggest that companies in large stock indices will be traded at a premium because these shares are more attractive for investors who replicate stock market indices, they are traded as underlying assets for options, and they benefit from flight to quality. A further discussion of this topic will not be necessary here because, unlike the marketability discount hypothesis, the stock index hypothesis can easily be tested by including a main stock index dummy variable in the empirical study.
} 
proxy for liquidity even though these variables are often used as liquidity proxies in other studies.

Koeplin, Sarin and Shapiro (2000) use a more direct approach to estimate illiquidity discounts. They simply compare publicly traded companies to similar private companies, which are acquisition targets, and compute an average illiquidity discount of $20-30 \% .{ }^{50}$ However, the study has some potential flaws. First of all, it is based on a relatively small sample distributed over a 15-year time period, and despite the researchers' efforts to compare similar companies, there are still differences in the characteristics of the two groups. Furthermore, it is not evident how the marketability discount can be separated from the general liquidity component in the analysis.

In practice, it does make a difference whether IIP compilers regard liquidity as a continuum or not. If liquidity is considered to be a continuum, a valuation model for unlisted equity could be based on data for listed equity, and the liquidity variable - such as trading volume or turnover ratio - could be set to zero for non-traded, unlisted equity. On the other hand, if compilers believe that a marketability discount should also be included, they would need to add a dummy variable to the model to catch the negative effect on value, which could be attributed to the fact that unlisted equity is not traded at an established trading platform. ${ }^{51}$ The empirical studies, however, have illustrated how difficult it is to measure illiquidity discounts and especially to split them into liquidity and marketability components. Alternatively, compilers could use transformations of the liquidity variable instead of assuming a linear relationship between prices and trading volume when estimating the valuation model. For instance, if they used the square root of trading volume instead of just trading volume, the marginal equity price effect would be decreasing with trading volume. This could in some sense be regarded as a compromise between the two approaches. In this

\footnotetext{
${ }^{50}$ The discount estimations are based on different valuation multiples and vary somewhat across multiples.

${ }^{51}$ Equation A2.1 shows a simple regression model where the marketability discount is identical for all unlisted equity, but the marketability discount is likely to be affected by size, number of potential buyers, asset and earnings volatility, asset structure, financial health of the company, etc. and will thus vary across unlisted equity. For instance, it would be reasonable to assume that the absolute marketability discount would be higher for large companies than for small companies, but the opposite may be true in relative terms. This hypothesis could be tested by including an interaction term between size and the dummy variable in the model.
} 
study, different transformations will be tested, but no explicit marketability discount will be introduced in addition to the liquidity variable.

\section{The Value of Control}

It is often seen that investors are willing to pay a premium for equity if they can gain control of a company. If one purely looks at the authority to manage a company's operations and disregard other considerations, the value of control can be defined as the premium that investors are willing to pay because they believe that they can operate a company better than it is currently done (Damodaran, 2005b). The control value (CV) of company $i$ is then given by:

$$
C V_{i}=V_{i}^{*}-V_{i}
$$

where $V_{i}^{*}$ is the value of company $i$ if it is optimally run, and $V_{i}$ is the value in a status quo situation. Therefore, it could potentially make a big difference whether the investor can acquire $49 \%$ or $51 \%$ of the voting power in a company. This is indeed the case if the investor's perception is that the acquisition target is poorly operated.

In addition to the strict definition of control value, there could be other aspects of control, which would be appealing to an investor. These aspects include private benefits, synergy, and strategic considerations. Private benefits are often observed in countries with low minority investor protection. Investors in such countries would be willing to pay a high premium for control because they can reap private benefits from their dominant position, for instance by selling goods and services to the company at an artificially high price. This way, they would lower the profit of the company, which would hurt minority investors. Synergy and strategic considerations are often involved when a company acquires a competitor within the same industry, and the existence of such potential gains may lead to the inclusion of a premium in a bidding process.

Control value is particularly interesting when valuing unlisted equity since many unlisted companies are $100 \%$ owned by a single investor or put more generally, unlisted companies typically have a much more limited ownership structure compared to listed companies. The BPM6 does not mention control premiums, but the BD4 (paragraph 297) indirectly mentions how they are treated in its description of ways to avoid asymmetry in the recording of listed equity. This paragraph states that the use of market price quotations 
ensures that all shares are valued at the same price. In other words, a $10 \%$ stake of the equity in a company is to be valued relatively at the same price as a $90 \%$ stake.

If an investor aims at acquiring another company, he would normally include a premium in his takeover bid to the existing shareholders if he could gain a controlling position in the target company. This seems to contradict international macroeconomic statistical manuals since the bid would depend on ownership share, indicating that, for instance, a $90 \%$ stake is valued at a relatively higher price than a $10 \%$ stake. However, one has to keep in mind that when an investor makes a bid to gain control of a company, the bid will usually be given to all current investors, regardless of their individual ownership share. Taking this view, it does make sense that all shares are valued at the same price. In the same sense, synergy and strategic considerations will be taken into account for all shares if these are included in the bidding price. Otherwise, they will not be included in the value of any share.

Regarding private benefits, these are different from other aspects of control, which can be seen as potential benefits for all investors. The difference is that only controlling investors gain from private benefits such as consumption of perquisites at the expense of the firm or an inappropriate use of transfer pricing to related parties. Therefore, it would not be reasonable to value all shares in such companies at the same price. However, shares in companies, where controlling investors are able to reap private benefits, would normally be divided into different share classes. These shares would trade at different prices, reflecting a combination of a lack of influence and the existence of private benefits. Since market prices for the share classes differ, the valuation of the shares would also differ in the IIP, and the private benefits would thus be taken into account.

In the literature, there are many studies that try to quantify the value of control. The basic studies simply look at the premiums paid in acquisitions and conclude that the control value is approximately 25\%. However, Hitchner (2006) argues that this premium also includes expected gains due to synergy and strategic considerations, and the pure control premium element as defined in Equation A2.2 is thus considerably smaller than 25\%. Furthermore, it will be misleading to apply a similar control premium to all equity since it varies across companies. It will ceteris paribus be high for inefficiently operated companies 
and low for well-managed companies. In the same way, it will be higher for companies where it is easy to make management or strategic changes than for other companies.

A number of studies have been made on price differentials between share classes. Zingales (1995) finds that voting shares in the US trade at a premium of 5-10\% over limitedvoting shares, indicating what investors are willing to pay for influence. Nenova (2003) also finds small premiums on control-block votes ${ }^{52}$ in the US, but she concludes that the premium varies significantly across countries. In countries with low minority investor protection, the premium can be as high as $48 \%$ while it is less than $1 \%$ in Denmark, Finland, and Sweden. This means that compilers in countries with a high degree of minority investor protection can disregard private benefits in their valuation models.

The question is how the control premium could be included in a valuation model for macroeconomic statistics. For both absolute and forward-looking relative valuation models, the potential effect of achieving better results by replacing inefficient management are included in the expected future earnings along with the probability that such replacement will happen. Moreover, the probability that a company will be acquired at a premium due to synergy effects or for strategic considerations should also be incorporated in the estimate.

The treatment in relative valuation models, which use past accounting data as input, is different. If the valuation models are estimated on listed companies and transferred to unlisted companies, it would change the parameter estimates in case an investor pays a control premium for listed equity. IIP compilers could include the largest investor's ownership share as an independent variable in the valuation model, and the price effect may be attributed to the fact that the company now has a large investor who is able to react faster to poor results and take the necessary actions. However, it may be the case that the new controlling investor has exactly the same ownership share as a former controlling investor, but he may still be willing to pay a premium because he can see new opportunities in the operation. In that case, a variable for the largest investor's ownership share will not pick up the price effect since this variable will remain unchanged. The relative valuation approach simply assumes that investors would also be willing to pay a similar premium for unlisted

\footnotetext{
${ }^{52}$ Nenova (2003) develops a measure to determine the premium, at which shares giving the first $50 \%$ of the voting power trade compared to the average share price for companies with dual-class voting rights. The analysis is carried out using data for 661 companies in 18 countries.
} 
equity with identical characteristics and be able to implement the same changes to run the private company more efficiently or achieve synergistic and strategic gains. This would explain the changes in parameter estimates.

Since a macro approach is used and the same price is applied to all shares within the same share class, the models can be applied to both unlisted direct investment equity and unlisted portfolio investment equity. However, as mentioned, care should be taken when applying models to minority shareholders in countries with low minority investor protection.

\section{Treatment of Negative Positions}

The value of listed equity has a lower limit of zero. Negative market prices are never observed on stock exchanges because shareholders are only liable for the value of the shares. However, companies that are listed on stock exchanges are globally consolidated enterprises, and direct investment enterprises that continually lose money, or that have liabilities exceeding their assets, may be sub-units of listed enterprises. The estimated market value for the individual money-losing direct investment enterprises could indeed be negative, in the case where their owner is willing to pay a prospective buyer to assume ownership.

In the case of unlisted direct investment equity, the treatment of negative positions generated by a valuation method is not straightforward. It may be argued that unlisted direct investment equity should be treated in the same way as listed equity, and negative positions should thus be revalued to zero. However, many direct investment enterprises are quasicorporations such as branches and notional units created for statistical purposes, and the direct investor would be liable for the debts of these units. In addition, many unlisted companies are fully owned by a single direct investor. It is occasionally seen that a parent company gives financial guarantees to a subsidiary in financial distress. In doing so, the subsidiary can stay in business because its creditors know that they will get their claims even in case of bankruptcy. In such cases, the parent company cannot liquidate its subsidiary without incurring a loss. Moreover, it is often seen that parent companies restore equity capital in subsidiaries in financial distress for reasons of reputation even though they are not required to do so by law.

The BPM6 (paragraph 7.19) recognizes that the value of a direct investment enterprise's non-equity liabilities may exceed its assets, and BPM6 allows the inclusion of 
negative equity positions under direct investment in the IIP. However, some individual country practices differ, and some countries do revalue negative equity positions in limited liability direct investment enterprises to zero.

Differences in the treatment of negative positions may have a significant impact on the figures used in the IIP. In principle, all compilers should use similar principles to determine market value for symmetry reasons. To make sure that the results will be symmetric, all countries should follow the statistical standard and accept negative values to be recorded under direct investment equity. However, this potential source for asymmetries could be avoided by simply recommending a valuation method that is not too much affected by the treatment of negative positions. 


\section{AnNeX 3: Model Assumptions}

Overall, the relative methods, price to earnings (Method C2) and price to book value (Method D), live up to the criteria for being used as valuation models for unlisted equity, but the two methods rely on four essential assumptions. These are assumptions are:

\section{- LOOP}

- Existence of comparables

- Transferability of model

- Projections outside data range

If the four assumptions are not fulfilled in general, it would not be reasonable to use the relative valuation methods to estimate a model for the valuation of unlisted equity. The idea behind the first assumption is that the LOOP must hold in the equity markets since it is the theoretical basis of the relative models. As mentioned, Levy Yeyati et al. (2006) find that price differences on financial markets are generally arbitraged away quickly. Capital controls can lead to more persistent price dispersions, but the valuation models will typically be generated from data within one economy. If the models were based on data from a region with inter-regional capital controls, IIP compilers would have to investigate the importance of these restrictions for asset pricing. For the Nordic data used in this study, however, the assumption of the LOOP is likely to hold. The reasons are the large number of investors in the market and the lack of capital restrictions in the region.

The second assumption is that it is possible to find comparables for unlisted companies. The BPM6 suggests the use of single-factor models with either earnings or book value as the independent variables. However, this may not be enough, and it is mentioned that the industry classification may also be taken into account. If IIP compilers use a regression approach, the models' coefficients of determination, $\mathrm{R}^{2}$, can be used as a tool to check the validity of the models. If $\mathrm{R}^{2}$ is low, the model does not seem to be able to explain the equity value variation, and the validity of the assumption, and thus the whole model, is

questionable. In other words, $\mathrm{R}^{2}$ is a measure for the value relevance of the factors in the 
model. ${ }^{53}$ For methods using central tendency measures to construct valuation multiples, the distribution of multiples can be analyzed. In principle, multiples for all companies should be identical for a correctly defined peer group. The estimation results in Section 4 will reveal whether or not this assumption is fulfilled. However, one has to keep in mind that the models estimated in this study will be used on the economy as a whole. If there are no systematic differences between listed and unlisted equity expect for those already included in the model (for instance liquidity), this may lead to an overestimation of some unlisted equity and an underestimation of other unlisted equity, but on an overall level, the data aggregation process will eliminate these differences. Therefore, IIP compilers will still be able to use a model even though the independent variables are not able to explain all variation in market values as long as there are no systematic differences between listed and unlisted companies.

The third assumption is that models based on listed companies can be transferred to unlisted companies. This assumption has three main practical implications. First, listed and unlisted companies must face identical potential earnings and future risks. For instance, this would not be the case if only listed companies were able to get lucrative contracts in certain business areas. The consequence would be that the models would lead to a general overestimation of the market value of unlisted equity. There are no indications that one group of companies would be favored over the other in terms of getting contracts in the Nordic countries. Similarly, the general risks in a given industry would be the same for listed and unlisted companies. Private companies may be operated differently due to the limited number of investors, but this effect would be embedded in earnings or other accounting variables rather than in the general business environment, which is identical for listed and unlisted companies in the Nordic countries.

The second implication is that the financial leverage ratio has to be similar for listed companies and unlisted companies if IIP compilers apply non-EV models to the latter. Basically, both types of companies face the same optimization problem when they decide on the degree of financial leverage. Taking future risk scenarios into account, companies will increase their debt if their expected return on assets is higher than their borrowing interest

\footnotetext{
${ }^{53}$ It is important to keep in mind that $\mathrm{R}^{2}$ will be upwards biased in the presence of scale effects. Therefore, $\mathrm{R}^{2}$ can only be used as an indicator of value relevance, and the analysis should also include a plausibility test of the parameter estimates.
} 
rate. Since tax rates do not differ between listed and unlisted companies in Denmark, the financial leverage ratios are ceteris paribus expected to be identical.

The third implication is that accounting regulations do not lead to systematic differences between accounting data for listed and unlisted companies. Within this context, tax authorities have to be in a position to prevent widespread inappropriate use of transfer pricing since its misuse is more likely to occur for unlisted companies and thus create a systematic bias. The same argument goes for the existence of private benefits, which affect accounting data and would typically occur more often in unlisted than listed companies. As shown by Nenova (2003), the minority investor protection is very high in the Nordic countries, especially in Denmark, Finland, and Sweden. Moreover, Danish tax regulations fully comply with the OECD's Transfer Pricing Guidelines. Companies in a group have to be able to document that intra-group transactions take place on an arm's-length basis.

On the issue of accounting principles, there is in fact a difference between the rules for listed and unlisted companies in the Nordic countries. In 2002, the European Union decided that listed companies had to draw up consolidated accounts based on the IFRS, beginning in 2005. This rule does not apply to unlisted companies, which are still allowed to use local GAAP. ${ }^{54}$ To avoid asymmetries stemming from differences in accounting standards, unconsolidated accounting data are used in this study since both listed and unlisted companies are only required to follow the local GAAP for these statements. Even if listed companies are more inclined to use IFRS for unconsolidated accounts than unlisted companies, the total effect on the model is likely to be diminutive. Vedran, Cazavan-Jeny, Jeanjean, and Weiss (2007) study the transition from local GAAP to IFRS for 1,964 companies in $7 \mathrm{EU}$ countries and only find small (but significant) changes in firms' net income and owners' equity. ${ }^{55}$

\footnotetext{
${ }^{54}$ However, most unlisted companies that are owned by listed foreign direct investors do in fact follow accounting rules applicable to listed companies as their accounts are used to draw up the accounts of the entire group.

${ }^{55}$ As a member of the European Economic Area, Norway implemented the same accounting standards for listed companies as the EU member states in 2005. Gjerde, Knivsflå, and Sættem (2007) analyze 145 Norwegian companies, which restated their 2004 accounts from Norwegian GAAP to IFRS. Their study shows that an unadjusted price regression with book value and earnings as independent variables resulted in an adjusted $\mathrm{R}^{2}$ of $80.5 \%$ for Norwegian GAAP and $79.2 \%$ for IFRS. This result indicates that the difference between following local GAAP and IFRS does not affect the value relevance of price models drastically.
} 
Even if the three practical implications for transferal of the model from listed to unlisted equity do not hold, it would still be possible to use the relative valuation models if systematic differences could be quantified. The reason is that such differences could be incorporated in the model by adjusting the parameter estimates. If non-systematic differences exist, IIP compilers would in principle be able to apply the model to unlisted companies, but the uncertainty about the market value estimates will be larger than in a situation with no accounting differences.

The fourth and final assumption is that it is possible to make realistic projections on companies outside the range of the input data. For instance, unlisted equity is less liquid than listed equity. Since valuation models are estimated on data for traded liquid equity, it has to be assumed that it is possible to project the relationship between market value and liquidity outside the data range of the liquidity variable. Moreover, unlisted companies tend to be smaller than listed companies, but the dataset includes listed companies with negative OFBV and with market capitalization as low as EUR 0.3 million. This means that there are observations for relatively small companies in the sample, which supports the assumption that the models can be transferred to unlisted equity.

The overall conclusion is that there are no obvious violations of the four assumptions behind the relative valuation models for the Nordic dataset. Despite basic differences in the reporting requirements and structural aspects for listed and unlisted companies, these should not have a systematic effect on the accounting figures, which would hamper the transferability of models estimated on listed companies to unlisted companies. Illiquidity discounts can be included directly in the models, and the dataset does include relatively small companies, making it possible to take size into account in the estimations. This means that in this study, the valuation models estimated on the basis of listed companies can be transferred to unlisted companies without making additional adjustments to the parameter estimates as the structural differences between listed and unlisted companies would already be included in the models. 


\section{Annex 4: Practical Estimation Considerations}

This annex describes some of the practical considerations that compilers need to take when estimating valuation models. Correlation tables should be studied in detail to check for multicollinearity, i.e. correlation between the independent variables, as it may lead to biased parameter estimates. Similarly, compilers need to make certain assessments when deciding on the variables to include in the models and how to test for scale effects.

\section{Correlation tables}

Correlations between the variables in the equity model are reported in Table A1. Pearson correlations are displayed above the diagonal and indicate the linear association between the variables. The non-parametric counterpart is Spearman's correlation measure, which is found below the diagonal. In general, Spearman correlations are considered to be a safer measure in case of non-linearity between variables (Meitner, 2006).

It can be seen that all potential independent variables are positively correlated with market value of equity, and this finding is in line with our expectations. Moreover, the correlation between OFBV and the earnings measures hovers around 0.6-0.7, which may lead to a risk of multicollinearity. As a rule of thumb, one has to be careful when including two independent variables with a correlation above 0.7 because it will be difficult to interpret the individual effects of the two independent variables on the dependent variable when they, to a large extent, convey the same information. Some regression models will be estimated on the industry level, and the intra-industry correlations will be different since they only include a fraction of the total data. In order to avoid multicollinearity issues, correlation coefficients between the independent variables should be monitored for each model.

Table A1: Correlations between variables in the equity model

\begin{tabular}{lrrrrrrr}
\hline Variable & \multicolumn{1}{c}{ MVE } & \multicolumn{1}{c}{ OFBV } & \multicolumn{1}{c}{ EARNS } & VOLUME & \multicolumn{1}{c}{ HOLD } & \multicolumn{1}{c}{ SUBS } & \multicolumn{1}{c}{ AGE } \\
\hline MVE & 1.00 & 0.78 & 0.75 & 0.55 & 0.05 & 0.39 & 0.25 \\
OFBV & 0.90 & 1.00 & 0.67 & 0.41 & 0.07 & 0.54 & 0.25 \\
EARNS & 0.59 & 0.56 & 1.00 & 0.31 & 0.03 & 0.35 & 0.27 \\
VOLUME & 0.37 & 0.34 & 0.05 & 1.00 & -0.04 & 0.18 & 0.10 \\
HOLD & 0.06 & 0.10 & 0.11 & -0.15 & 1.00 & -0.05 & 0.08 \\
SUBS & 0.62 & 0.67 & 0.38 & 0.32 & 0.02 & 1.00 & 0.31 \\
AGE & 0.22 & 0.28 & 0.28 & -0.10 & 0.14 & 0.35 & 1.00 \\
\hline
\end{tabular}

Notes: Variable definitions can be found in Table 3 Pearson (Spearman) correlations are reported above (below) the diagonal Source: Calculations based on data from Bureau van Dijk's ODIN Database 
Table A2 shows correlations between variables in the EV model. As mentioned in Section 2A, we use earnings measures, which flow to all providers of capital. This is done to avoid the inclusion of spurious variables, which potentially would result in biased results. It can be seen that all independent variables are also positively correlated with EV as expected. Multicollinearity may become a problem if revenue and EBIT are included in the same model since the Pearson correlation coefficient is as high as 0.85 . Furthermore, the correlation between OFBV and EBIT is high at the aggregate level and should be monitored in the regression models.

Table A2: Correlations between variables in the EV model

\begin{tabular}{lcrrrrrrr}
\hline Variable & EV & \multicolumn{1}{c}{ OFBV } & \multicolumn{1}{c}{ EBIT } & REVENUE & VOLUME & HOLD & \multicolumn{1}{c}{ SUBS } & AGE \\
\hline EV & 1.00 & 0.84 & 0.70 & 0.66 & 0.55 & 0.06 & 0.44 & 0.25 \\
OFBV & 0.90 & 1.00 & 0.66 & 0.52 & 0.41 & 0.07 & 0.54 & 0.25 \\
EBIT & 0.08 & 0.00 & 1.00 & 0.85 & 0.19 & 0.03 & 0.26 & 0.25 \\
REVENUE & 0.56 & 0.50 & 0.48 & 1.00 & 0.15 & 0.03 & 0.21 & 0.21 \\
VOLUME & 0.31 & 0.34 & -0.24 & 0.04 & 1.00 & -0.04 & 0.18 & 0.10 \\
HOLD & 0.07 & 0.10 & 0.04 & 0.06 & -0.15 & 1.00 & -0.05 & 0.08 \\
SUBS & 0.62 & 0.67 & -0.01 & 0.34 & 0.32 & 0.02 & 1.00 & 0.31 \\
AGE & 0.23 & 0.28 & 0.19 & 0.36 & -0.10 & 0.14 & 0.35 & 1.00 \\
\hline
\end{tabular}

Note: Variable definitions can be found in Table 3. Pearson (Spearman) correlations are reported above (below) the diagonal

Source: Calculations based on data from Bureau van Dijk's ODIN Database

\section{Selection of Earnings Measure}

Prior to the estimation of the earnings valuation models, we need to select the earnings measure that will be used in the models. Table A3 contains descriptive statistics for five different earnings measures. They are all trailing accounting figures since it will be difficult to obtain valid forecasts for future earnings for unlisted companies.

Table A3: Descriptive statistics for earnings measures in the dataset (EUR million)

\begin{tabular}{|c|c|c|c|c|c|c|}
\hline Name & Description & Obs. & Mean & Std. dev. & Minimum & Maximum \\
\hline EARNS & $\mathrm{P} / \mathrm{L}$ before taxes & 681 & 72.0 & 422.8 & -637.0 & $7,404.0$ \\
\hline AT_PL & $\mathrm{P} / \mathrm{L}$ after taxes & 682 & 64.9 & 389.9 & -637.0 & $6,650.0$ \\
\hline AT_PL1 & Lagged AT_PL & 666 & 46.0 & 220.9 & -306.0 & $2,591.4$ \\
\hline AT_PLA3 & Average AT_PL for last 3 years & 644 & 49.5 & 241.0 & -263.2 & $3,836.7$ \\
\hline FINAL_PL & $\mathrm{P} / \mathrm{L}$ after taxes and extraordinary items & 681 & 69.5 & 393.9 & -548.0 & $6,683.0$ \\
\hline
\end{tabular}

Source: Calculations based on data from Bureau van Dijk's ODIN Database 
The first step in the selection process is to estimate five univariate regression models with one of the earnings measures as independent variable in each model. The regression diagnostics are displayed in Table A4, and it can be seen that the model including average after-tax earnings for the last three years (AT_PLA3) has the highest $\mathrm{R}^{2}$. Even though an exact model comparison cannot be made due small sample differences, it indicates that average earnings is a better predictor for market value of equity than the other earnings measures.

Table A4: Regression models on market value of equity using different earnings measures

\begin{tabular}{|c|c|c|c|c|c|}
\hline & EARNS & AT_PL & AT_PL1 & AT_PLA3 & FINAL_PL \\
\hline $\mathrm{B}_{0}$ (intercept) & 528.07 & 555.42 & 386.53 & 361.50 & 525.16 \\
\hline Stand error & 118.20 & 138.14 & 102.80 & 75.70 & 146.17 \\
\hline t-value & 4.47 & 4.02 & 3.76 & 4.78 & 3.59 \\
\hline $\mathrm{B}_{1}$ (earnings) & 7.17 & 7.50 & 14.52 & 14.35 & 7.46 \\
\hline Stand error & 2.39 & 3.12 & 3.74 & 2.48 & 3.06 \\
\hline t-value & 3.00 & 2.41 & 3.88 & 5.78 & 2.44 \\
\hline Observations & 681 & 682 & 666 & 644 & 681 \\
\hline $\mathrm{R}^{2}$ & 0.56 & 0.52 & 0.61 & 0.69 & 0.53 \\
\hline
\end{tabular}

The BPM6 (paragraph 7.16c) suggests that earnings valuation models may be estimated at the industry level because risks and potential earnings and thus $\mathrm{P} / \mathrm{E}$ ratios vary across industries. In Table A5, the coefficients of determination are displayed for industry-level models. The table reveals that the average $\mathrm{R}^{2}$ for the industry group models is higher than the $\mathrm{R}^{2}$ for the joint model, which supports the hypothesis of varying $\mathrm{P} / \mathrm{E}$ ratios. ${ }^{56} \mathrm{It}$ can also be seen that the models including average after-tax earnings for the past three years give the best fit, followed by the before-tax-earnings models. Interestingly, the order of best-performing earnings measure changes from year to year, and in models based on data for 2004 (not displayed in the table), earnings after extraordinary losses and gains is the best predictor followed by earnings before taxes. This finding suggests that we should use different earnings measures from year to year, but for practical reasons, this would not be feasible.

\footnotetext{
${ }^{56}$ However, it should be noted that comparisons of $\mathrm{R}^{2}$ values between different samples are connected with great uncertainty as pointed out by Brown et al. (1999).
} 
Data for unlisted companies often come from surveys, and it is not possible to change the survey questions every year. Average earnings generally perform better than earnings before taxes in the period 2004-2006, but we will use the latter since it is easier to collect data from one year than a 3-year average. ${ }^{57}$ It may be surprising that earnings before taxes perform better than earnings after taxes, but the reason could be that tax regulations and tax rates change over time. Therefore, investors put more emphasis on gross earnings potential than net earnings.

Table A5: $R^{2}$ in regression models on market value of equity by industry group

\begin{tabular}{lrrrrr}
\hline Industry group & EARNS & AT_PL & AT_PL1 & AT_PLA3 & FINAL_PL \\
\hline Group 1 & 0.844 & 0.838 & 0.921 & 0.892 & 0.805 \\
Group 2 & 0.622 & 0.559 & 0.661 & 0.761 & 0.684 \\
Group 3 & 0.785 & 0.503 & 0.921 & 0.910 & 0.509 \\
Group 4 & 0.843 & 0.835 & 0.600 & 0.895 & 0.835 \\
Group 5 & 0.934 & 0.942 & 0.968 & 0.959 & 0.954 \\
Group 6 & 0.367 & 0.371 & 0.282 & 0.547 & 0.371 \\
Average & 0.732 & 0.674 & 0.725 & 0.827 & 0.693 \\
& & & & & \\
All industries & & & & & \\
Source: Calculations based on data from Bureau van Dijk's ODIN Database & & \\
\end{tabular}

\section{Model Selection Procedure}

As mentioned in Section 3B, scale differences may affect the result of the estimations. Extreme observations tend to dominate parameter estimates and cause an upward bias in $\mathrm{R}^{2}$. One way to test for scale effects is to estimate models for different data ranges and compare the results to the overall model. The data ranges can be defined by a number of variables, but we have chosen to use OFBV. Thus, the data set is split into four quarters, according to size of OFBV, and the models for each quarter are displayed in Table A6.

\footnotetext{
${ }^{57}$ Table A3 reveals that the average earnings are missing for 38 companies while before-tax earnings are observed for all companies except for one. Obviously, missing values are more likely to be observed for variables based on average or lagged values because such values do not exist for newly established or restructured companies.
} 
Table A6: Regression models on market value of equity for different $O F B V$ data ranges

\begin{tabular}{lrrrrr}
\hline & Joint estimation & First quarter & Second quarter & Third quarter & Fourth quarter \\
\hline $\mathrm{B}_{0}$ (intercept) & 528.07 & 26.22 & 85.35 & 201.37 & 1922.54 \\
Stand error & 118.2 & 4.08 & 7.82 & 38.42 & 500.79 \\
t-value & 4.47 & 6.42 & 10.92 & 5.24 & 3.84 \\
& & & & & \\
$\mathrm{~B}_{1}$ (EARNS) & 7.17 & 1.94 & 6.22 & 9.25 & 6.64 \\
Stand error & 2.39 & 1.43 & 1.99 & 4.42 & 2.58 \\
t-value & 3.00 & 1.37 & 3.13 & 2.09 & 2.57 \\
Observations & 681 & 171 & 169 & 171 & 170 \\
$\mathrm{R}^{2}$ & & & & & \\
Source: Calculations based on data from Bureau van Dijk's ODIN Database & & & \\
\end{tabular}

It can be seen that the intercept varies significantly across models whereas differences in earnings parameter estimates are not statistically significant. The model for companies in the lowest OFBV quarter has a very low $\mathrm{R}^{2}$, which may be explained by the fact that the group is quite heterogeneous. Some companies are newly started, and they may have promising outlooks for the future. In that case, market values will be relatively high even if the companies have small or negative earnings. In contrast, other companies in the same group may be in financial distress after having had negative earnings for a longer period of time. Naturally, these companies will be valued at a low level, and the group heterogeneity would thus explain the low coefficient of determination.

Even though a better data fit can be achieved by estimating models for different data ranges, joint size estimations are chosen for two reasons. The first reason is that some models would be based on a very small number of observations if data were split into industry as well as size groups. The second reason is that an increase in the number of models will make a worldwide implementation of the valuation model more unlikely.

In the final step of the model estimation process, we have to make some additional choices. As suggested in the international statistical manuals, trading volumes are included as a liquidity proxy, which causes an increase in the adjusted $\mathrm{R}^{2}$. The stock market index dummy variable also positively affects the adjusted $\mathrm{R}^{2}$ whereas both the country dummy variable and the interaction terms between the dummy variables and quantitative variables are dropped because they have a negative effect on the adjusted $\mathrm{R}^{2}$. Similarly, we have tried to include log and square root transformations of trading volume, but with a lower average $\mathrm{R}^{2}$ 
as a result. Lastly, we will impose the restriction that the regression has to go through the origin. The reason for this is that the intercept as well as the other parameter estimates will be affected by large values as is seen in Table A6. Therefore, the contribution from the independent variables will be dwarfed by the intercept for small companies, and since unlisted companies are smaller than listed companies on average, the inclusion of an intercept would lead to a bias when applied to unlisted direct investment equity. The final multi-factor models with earnings, trading volume, and the stock market index variable can be seen in Table A7.

Table A7: Multi-factor regression models on market value of equity by industry group

\begin{tabular}{|c|c|c|c|c|c|c|c|}
\hline & All industries & Group 1 & Group 2 & Group 3 & Group 4 & Group 5 & Group 6 \\
\hline $\mathrm{B}_{1}(\mathrm{EARNS})$ & 5.27 & 4.17 & 6.94 & 4.27 & 3.88 & 22.34 & 0.37 \\
\hline Stand error & 2.78 & 27.19 & 3.52 & 3.25 & 1.45 & 5.54 & 2.76 \\
\hline t-value & 1.89 & 0.15 & 1.97 & 1.31 & 2.68 & 4.03 & 0.13 \\
\hline $\mathrm{B}_{2}(\mathrm{VOL})$ & $1.32 \mathrm{E}-02$ & $6.64 \mathrm{E}-02$ & $1.62 \mathrm{E}-02$ & $1.50 \mathrm{E}-03$ & $1.35 \mathrm{E}-02$ & $3.32 \mathrm{E}-03$ & $3.16 \mathrm{E}-02$ \\
\hline Stand error & $6.88 \mathrm{E}-03$ & $6.53 \mathrm{E}-02$ & $3.70 \mathrm{E}-02$ & $2.00 \mathrm{E}-03$ & $1.35 \mathrm{E}-02$ & $5.88 \mathrm{E}-03$ & $2.72 \mathrm{E}-02$ \\
\hline t-value & 1.91 & 1.02 & 0.44 & 0.75 & 1.00 & 0.56 & 1.16 \\
\hline $\mathrm{B}_{3}(\mathrm{INDEX})$ & 3545.80 & 5018.00 & 3134.84 & 2508.87 & 1216.07 & 1413.83 & 3368.76 \\
\hline Stand error & 1035.18 & 5054.99 & 882.27 & 2163.25 & 599.89 & 2193.86 & 1206.13 \\
\hline t-value & 3.43 & 0.99 & 3.55 & 1.16 & 2.03 & 0.64 & 2.79 \\
\hline Observations & 653 & 96 & 142 & 85 & 52 & 146 & 132 \\
\hline Adjusted $\mathrm{R}^{2}$ & 0.74 & 0.96 & 0.78 & 0.83 & 0.88 & 0.95 & 0.77 \\
\hline
\end{tabular}

The coefficient of determination is often used as a model evaluation tool, but even though it is generally high for the multi-factor earnings models, it does not mean that the models are flawless. For instance, the heteroscedasticity corrected standard errors are rather high for the earnings variable, which means that only half of the industry group level $\mathrm{P} / \mathrm{E}$ models include a statistically significant earnings measure. There are three reasons for that. The first reason is the limited number of observations in the model. The standard error decreases with the number of observations, and simply by adding more data to the model, we will get more significant parameter estimates. The second reason is that the correlation between the independent variables is up to $90 \%$ in some industry group level models, which causes multicollinearity issues and more instability in parameter estimates. The third and 
most important reason is that trailing earnings measures are simply not a high-quality predictor for future earnings. Earnings are volatile, and $37 \%$ of the companies in our sample display negative before-tax earnings. Still, they all have a positive market value, indicating that future earnings will generally be positive according to the DCF models. It could be argued that the 3-year average would mitigate the volatility problem significantly. However, it turns out that this variable takes on a negative value for $34 \%$ of all observations.

Moreover, when we consider the size of the earnings parameter estimates, it varies significantly across industries. The lowest is 0.37 , and the highest is 22.34 . If investors buy a 1-year risk-free government debt instrument at par value with an interest of $4 \%$, they pay EUR 25 per leading earned euro. Since equity earnings are generally more volatile, we would expect that investors are willing to pay less for equity. However, a $\mathrm{P} / \mathrm{E}$ ratio of 0.37 on the industry level is unrealistically low and signals that a drastic decline in earnings is expected ${ }^{58}$ or, more likely, that the earnings parameter estimate is heavily affected by multicollinearity or omitted variables.

The practical considerations for the OFBV equity valuation models and the multifactor models on market value of equity and EV are similar to the ones presented above and will not be presented here.

\footnotetext{
${ }^{58}$ For instance, this could be the case if the profits of the financial year used in the calculations were heavily affected by large one-time capital gains. However, it is not realistic that the effect would be this significant at the industry group level.
} 


\section{ANNEX 5: DESCRIPTIVE STATISTICS FOR UNLISTED DiRECT INVESTMENT ENTERPRISES}

Table A8: Descriptive statistics for unlisted Danish direct investment enterprises

\begin{tabular}{|c|c|c|c|c|c|c|}
\hline Industry group & Obs. & Mean & Std. deviation & Min & Max & Non-positive values \\
\hline & \multicolumn{6}{|c|}{ Earnings before taxes } \\
\hline Group 1 & 265 & 0.4 & 5.3 & -20.2 & 63.7 & 96 \\
\hline Group 2 & 432 & 2.3 & 10.7 & -47.0 & 135.0 & 129 \\
\hline Group 3 & 1302 & 0.9 & 5.9 & -31.0 & 79.0 & 388 \\
\hline Group 4 & 212 & 4.0 & 34.0 & -246.7 & 310.1 & 85 \\
\hline Group 5 & 528 & 0.6 & 3.0 & -13.2 & 31.1 & 220 \\
\hline Group 6 & 423 & 4.0 & 45.5 & -300.7 & 424.8 & 176 \\
\hline \multirow[t]{2}{*}{ All industries } & 3162 & 1.6 & 19.7 & -300.7 & 424.8 & 1094 \\
\hline & \multicolumn{6}{|c|}{$O F B V$} \\
\hline Group 1 & 266 & 6.9 & 37.8 & -18.4 & 469.3 & 52 \\
\hline Group 2 & 432 & 12.4 & 74.6 & -17.7 & $1,444.3$ & 52 \\
\hline Group 3 & 1308 & 5.8 & 41.7 & -73.0 & 1264.1 & 182 \\
\hline Group 4 & 216 & 28.9 & 184.5 & -13.6 & $2,288.0$ & 34 \\
\hline Group 5 & 536 & 3.7 & 15.1 & -34.7 & 231.6 & 99 \\
\hline Group 6 & 426 & 75.0 & 213.1 & -71.6 & 2886.6 & 50 \\
\hline All industries & 3184 & 17.3 & 102.7 & -73.0 & 2886.6 & 469 \\
\hline
\end{tabular}

Note: Financial institutions and insurance companies are not included in the data.

Source: Calculations based on data from Bureau van Dijk's ODIN Database 


\section{Annex 6: Practical Advice for Compilers}

FDI compilers are faced with a number of practical issues when deciding on i) the valuation method and ii) the estimation technique. ${ }^{59}$ Regarding the choice of valuation method, it is clear that all seven BPM6-recommended methods have their strengths and weaknesses. This study has shown that the price-to-book value method (Method D) best takes into account the four criteria of objectivity, general applicability, robustness, and reliability when applied to Danish data. ${ }^{60}$ The picture may be different in other countries, and compilers are encouraged to test more than one valuation method to get a feeling for the sensitivity of the results.

Similarly, compilers should test the robustness of the valuation methods. In general, compilers should be extremely careful about the direct use of level-based regression models as such estimations are likely to be affected by scale effects, which hamper the quality of the empirically estimated models. One way to check for scale effects is to assess the plausibility of the parameter estimates. For instance, negative parameter estimates for earnings or OFBV in a model regressed on market price of equity would typically be an indication of scale effects. In such cases, it is recommended to apply central tendency measures for valuation multiples instead. Compilers should use the valuation multiples with the lowest dispersion; the practical experiences in the case of Denmark has shown that the dispersion for $\mathrm{P} / \mathrm{B}$ ratios is smaller than for $\mathrm{P} / \mathrm{E}$ and $\mathrm{EV} / \mathrm{EBIT}$ ratios, indicating that $\mathrm{P} / \mathrm{B}$ models are most robust and better valuation predictors than earnings multiples at the aggregate level. Finally, it is worth mentioning that data should only be published at an aggregate level.

\footnotetext{
59 Figure A1 shows the relations between the theoretical issues, the practical recommendations given in the BPM6, and the terminology and estimation techniques applied in the empirical section.

${ }^{60}$ The criteria of objectivity and general applicability are discussed in Section 3A and the criteria of robustness and reliability in Section $4 \mathrm{E}$.
} 
Figure A1: Relations between equity valuation theory, BPM6 methods and empirical estimation

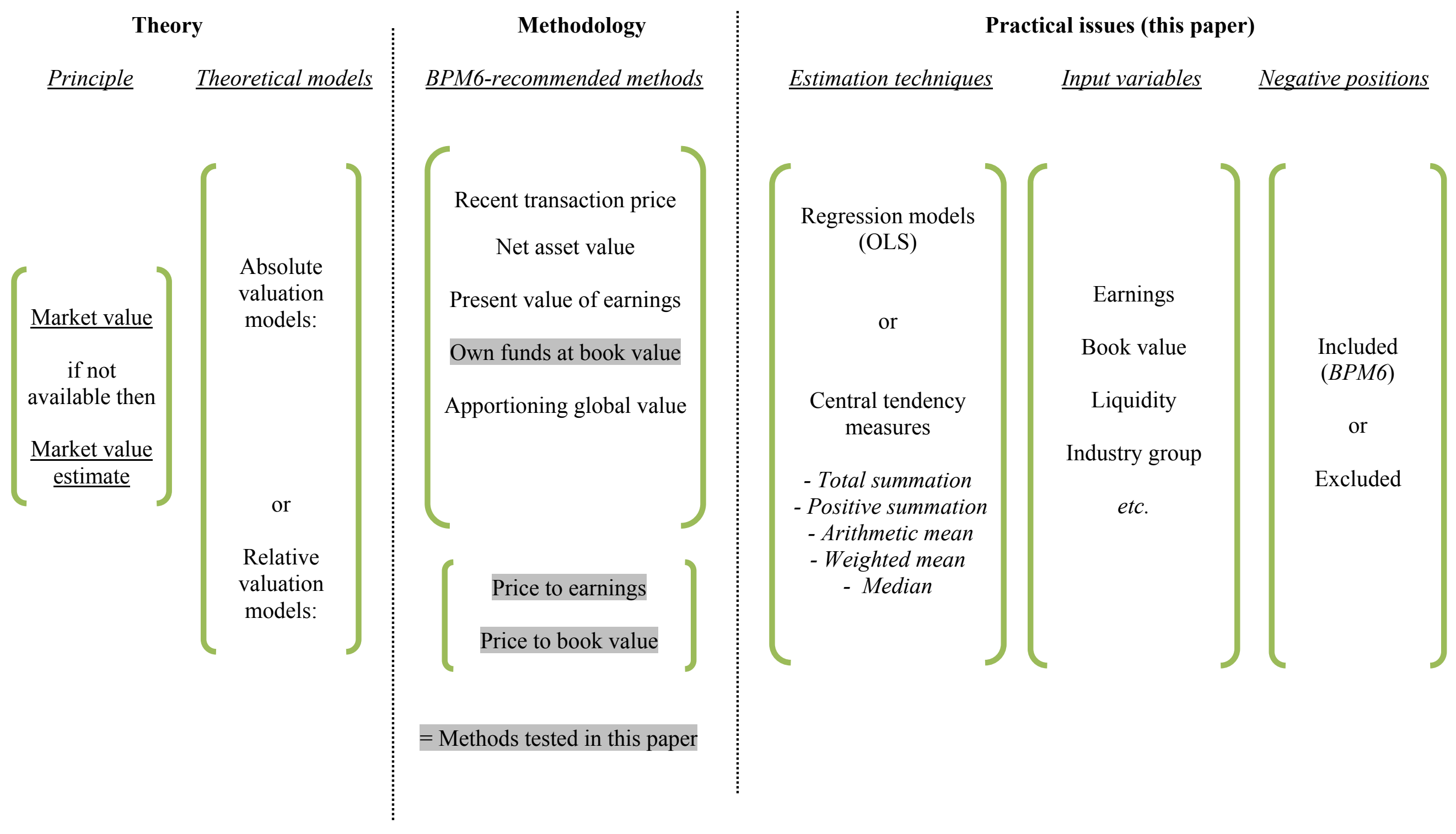

